\title{
Syntheses and chromotropic behavior of two halo bridged dinuclear copper(II) complexes containing pyridine-based bidentate ligand
}

\author{
Atie Shirvan ${ }^{1}$, Hamid Golchoubian ${ }^{1 *}$, Elisabeth Bouwman ${ }^{2}$ \\ 1. Department of Chemistry, University of Mazandaran, Babol-sar, Iran. Postal Code 47416- \\ 95447 \\ 2. Leiden Institute of Chemistry, Gorlaeus Laboratories, Leiden University, P.O. Box 9502, 2300 \\ RA Leiden, the Netherlands \\ Reprint requests to Dr. H. Golchoubian. \\ Tel/ Fax: +(98) (112) 5342350 \\ E-mail: h.golchobian@umz.ac.ir
}

\begin{abstract}
Two dinuclear doubly bridged copper(II) complexes $[\mathrm{LCu}(\mu-\mathrm{Cl}) \mathrm{Cl}]_{2}(\mathbf{1})$ and $[\mathrm{LCu}(\mu-\mathrm{Br}) \mathrm{Br}]_{2}$ (2), where L represents N-benzyl(pyridine-2-yl)methaneamine, have been synthesized to investigate their chromotropic behavior. The structures of the complexes were characterized by elemental analyses, various spectroscopic techniques (IR, UV-Vis, and EPR), molar conductance measurements and thermal analysis. The crystal structure of compound $\mathbf{1}$ indicated both copper(II) centers are located in $\mathrm{N}_{2} \mathrm{Cl}_{3}$ environments with distorted square pyramidal geometries, which sharing one base to apex edge. The complexes are chromotropic and their solvatochromism, halochromism, and thermochromism properties were investigated by visible absorption spectroscopy. The solvatochromic properties of the complexes are attributed to structural changes in various solvents. Their halochromism phenomena arise from protonation and deprotonation of coordinated ligands in the $\mathrm{pH}$ range of 2.0-10.5, and the reversible thermochromism in DMF and DMSO solutions is triggered by replacing the ligands by solvent molecules.
\end{abstract}

Keywords: Thermochromism; Halochromism; Solvatochromism; Copper(II); Dinuclear 


\section{Introduction}

During the last decades, chromotropism of coordination compounds have become subject of interest due to their potential applications in the field of sensors and molecular switches materials [1-5]. Numerous studies have been carried out on the chromotropism behavior of the transition metal complexes to investigate the correlation between these properties and the structural characteristics [1, 5-7]. Among the coordination compounds, copper(II) complexes with a combination of the proper organic ligand are a suitable candidate for practical applications of chromotropism, due to their various geometrical structures, diverse coordination numbers, and presence of strong Jahn-Teller effect. Several classes of mixed-chelate copper(II) complexes containing unsaturated coordination sphere of central ion have been synthesized and their solvatochromism properties were investigated [8, 9]. However, the color intensity of these compounds is low since the origin of their color variation arises from the d-d transition of $\mathrm{Cu}(\mathrm{II})$ ion. Thus, the preparation of chromotropic probes with higher molar absorptivity is extremely desirable. This disadvantage can be improved in di- or multi-nuclear compounds. On the other hand, our study on the penta-coordinated copper(II) complexes showed that the solvatochromism property is sensitive to the structural geometry of the copper center $[10,11]$. So that a change in the structure of the compounds from square pyramid to trigonal bipyramid the solvatochromism property almost vanishes [12]. On the other hand, the structural feature of copper complexes is influenced by the nature of co-ligands and their steric crowding imposed around the metal center. It was found that utilizing a chelate ligand with bulky substituents suppresses the formation of the homoleptic mononuclear complexes and bridging dinuclear halo- or hydroxo complexes form [13]. However, an increase in the bulkiness of substituents causes a deviation in the geometry of copper(II) complex from square pyramidal to trigonal bipyramidal. Therefore, a compromise must be taken into account in the selection of the degree of the bulkiness of the chelate ligand and the structural features of the copper complex. On the other hand, it is well known that the coordination of a secondary amine moiety to a metal ion enhances its acidity power and the resultant complex becomes sensitive to the $\mathrm{pH}$ in aqueous solution and shows halochromism. The resultant ionized amine changes the color of the solution due to change in the ligand field strength around the metal center. In particular, the repeatable conversion between deprotonation and protonation of the coordinated amine ligand in response to the $\mathrm{pH}$ value of the solution is accompanied by spectral change. In addition, Many mixed-ligand copper(II) chloride and 
bromide complexes demonstrated thermochromic behavior $[12,14,15]$ when small differences in their electronic properties are reflected in the structures that they prefer upon heating. Presence of Jahn-Teller effect and also other weakly bounded ligand make copper(II) complexes susceptible to exhibit chromotropism.

The present work reports on the preparation of two new dinuclear halo bridged copper(II) complexes with the formula $\left[\mathrm{LCu}(\mu-\mathrm{X})_{2} \mathrm{X}\right]_{2}(\mathrm{X}=\mathrm{Cl}, \mathrm{Br})$ where $\mathrm{L}$ is $N$-benzyl(pyridine-2yl)methaneamine. These complexes exhibit thermochromism, solvatochromism, and halochromism collectively. Synthesis, structure and chromotropism behavior of the compounds have described below.

\section{Experimental}

\subsection{Materials and physical measurements}

All chemicals and reagents were purchased from commercial sources and used as received. The solvents used in the solvatochromic study were spectroscopic grade and as follows: nitromethane (NM), nitrobenzene (NB), methanol (MeOH), ethanol (EtOH), dichloromethane (DCM), acetonitrile (AN), benzonitrile (BN), pyridine (Py) dimethylformamide (DMF), dimethylsulfoxide (DMSO), and hexamethylphosphorictriamide (HMPA). The C, $\mathrm{H}$, and $\mathrm{N}$ elemental analyses were carried out on a Perkin Elmer model 2400 elemental analyzer. The infrared spectra were recorded in a range of $400-4000 \mathrm{~cm}^{-1}$ using a Bruker FT-IR instrument in pellets with KBr. ${ }^{1} \mathrm{H}$ and ${ }^{13} \mathrm{C}$ NMR spectra were acquired on a Bruker $400 \mathrm{MHz}$ DRX Fourier Transform Spectrometer at room temperature. Conductance measurements were made at $25{ }^{\circ} \mathrm{C}$ with a Jenway 400 conductance meter on $1.00 \times 10^{-3} \mathrm{M}$ samples in selected solvents. The electronic absorption spectra of solutions were measured with a Varian Cary50 spectrophotometer using $1 \mathrm{~cm}$ quartz cells. UV-Vis spectra of powder samples were collected using Avantes Avaspec spectrometer with Avalight-DH-S-BAL light source. Thermogravimetric analyses of complexes were performed using Bahr Thermo Analyse STA 504 instrument in an argon atmosphere. The X-band electron paramagnetic resonance (EPR) spectrum was recorded in a Bruker X-band spectrometer operating at a field modulation of $100 \mathrm{kHz}$ at $80 \mathrm{~K}$. 


\subsection{Synthesis}

\subsection{1. $N$-benzyl(pyridine-2-yl)methaneamine (L)}

A mixture of pyridine-2-carbaldehyde (1.9 ml, $20 \mathrm{mmol})$, 1-phenylmethaneamine (2.2 ml, 20 $\mathrm{mmol}$ ) and a few drops of acetic acid in methanol $(30 \mathrm{ml})$ was prepared and refluxed for $10 \mathrm{~min}$. Solid $\mathrm{NaBH}_{4}$ (1.1 g, $30 \mathrm{mmol}$ ) was then added gradually to the resulted solution over a period of $30 \mathrm{~min}$ and the mixture was allowed to stand overnight. After heating the solution to near the boiling point, $\mathrm{HCl}(6 \mathrm{ml}, 17 \mathrm{M})$ was added to it dropwise, while placing the solution in an ice bath. The mixture was then made alkaline $(\mathrm{pH}=8)$ by adding $\mathrm{NaOH}(25 \mathrm{~mL}, 4 \mathrm{M})$. The sodium borate precipitate was removed by filtration and the filtrate was concentrated to obtain a brown oil which was subsequently extracted with dichloromethane $(3 \times 15 \mathrm{~mL})$. The combined organic fractions were dried over anhydrous $\mathrm{Na}_{2} \mathrm{SO}_{4}$. Evaporation of the solvent under reduced pressure resulted in the desired product as pale brown oil. The yield was $3.48 \mathrm{~g}(88 \%)$. Selected IR data (v/cm ${ }^{-1}$ using KBr disk): 3313 (br, s, N-H str.); 3061, 3028 (s, C-H aromatic); 2917, 2837 (s, C-H aliphatic); 1593 (s, C=N str.); 1435 (s, C=C str.); 1118 (m, C-N str. aliphatic); 755(s); 700(s). ${ }^{1} \mathrm{H}$

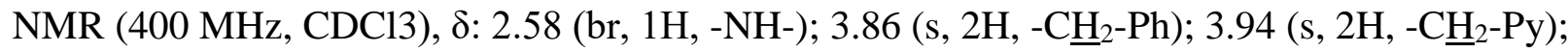
7.17 (m, 1H, Ph); 7.27 (m, 1H, Ph); 7.34 (m, 3H, Ph); 7.37 (m, 2H, Py); 7.65 (t,d, J = 7.6, 1.6 $\mathrm{Hz}, 1 \mathrm{H}, \mathrm{Py}) ; 8.57$ (d, $J=4.0 \mathrm{~Hz}, 1 \mathrm{H}, \mathrm{Py}$ ). When one drop of $\mathrm{D}_{2} \mathrm{O}$ was added to the ${ }^{1} \mathrm{H}-\mathrm{NMR}$ sample, the broad signal at $2.58 \mathrm{ppm}$ disappeared. ${ }^{13} \mathrm{C}$ NMR (100 MHz in $\left.\mathrm{CDCl}_{3}\right), \delta: 53.39$ (NH- $\left.{ }_{-} H_{2}-\mathrm{Py}\right) ; 53.45$ (-NH- $\left.{ }_{-} H_{2}-\mathrm{ph}\right) ; 122.01,122.43,136.50,149.29,159.55$ (Py-C); 127.04, 128.30, 128.43, 139.94 (C-Ph).

2.2.2. $\operatorname{Bis}\left(\left(\mu\right.\right.$-chloro)chloro, $N$-benzyl(pyridine-2-yl)methaneamine copper(II)), $\left[\mathrm{LCu}(\mu \text {-Cl)Cl }]_{2}\right.$

To the solution of ligand L (0.396 g, $2 \mathrm{mmol})$ in methanol $(7 \mathrm{~mL})$ was slowly added a solution of $\mathrm{CuCl}_{2} \cdot 2 \mathrm{H}_{2} \mathrm{O}(0.34 \mathrm{~g}, 2 \mathrm{mmol})$ in methanol $(5 \mathrm{~mL})$. The resultant bluish-green mixture was stirred for $3 \mathrm{~h}$ at room temperature. The desired compound precipitated from the solution as blue solid and separated by filtration. The obtained product was recrystallized by diffusion of diethyl ether into a methanol solution. The typical yield was $60 \%$ ( $0.40 \mathrm{~g})$. The crystals were suitable for $\mathrm{X}$-ray crystal structure determination. Anal. Calcd for $\mathrm{C}_{26} \mathrm{H}_{28} \mathrm{~N}_{4} \mathrm{Cu}_{2} \mathrm{Cl}_{4}\left(\mathrm{MW}=665.43 \mathrm{~g} \mathrm{~mol}^{-1}\right)$ : C, 46.93; H, 4.24; N, 8.42\%; Found: C, 46.40; H, 4.17; N, 8.30\%. Selected IR data $\left(v / \mathrm{cm}^{-1}\right.$ using 
KBr disk): 3175 (s, N-H str.); 3069 (m, C-H str. aromatic); 2924, 2870 (m, C-H str. aliphatic); 1607 (s, C=N str.); 1484 (m, C=C str.); 1450 (s, C-H bend.); 1095 (m); 1054 (m); 1021 (m); 755 (s); $705(\mathrm{~m})$.

2.2.3. Bis(( $\mu$-bromo)bromo, $N$-benzyl(pyridine-2-yl)methaneamine copper(II)), $[\mathrm{LCu}(\mu \text {-Br }) \mathrm{Br}]_{2}$

This compound was prepared according to the procedure used for $[\mathrm{LCu}(\mu-\mathrm{Cl}) \mathrm{Cl}]_{2}$, except that $\mathrm{CuBr}_{2}$ was used $(0.45 \mathrm{~g}, 2 \mathrm{mmol})$ in place of $\mathrm{CuCl}_{2} \cdot 2 \mathrm{H}_{2} \mathrm{O}$. The complex was obtained as a green solid with a typical yield of 53\% (0.45 g). Anal. Calcd for $\mathrm{C}_{26} \mathrm{H}_{28} \mathrm{~N}_{4} \mathrm{Cu}_{2} \mathrm{Br}_{4}(\mathrm{MW}=843.24 \mathrm{~g}$ $\left.\mathrm{mol}^{-1}\right)$ : C, 37.03; H, 3.35; N, 6.64\%; Found: C, 37.18; H, 3.12; N, 6.66\%. Selected IR data (v/cm ${ }^{1}$ using KBr disk): 3195 (s, N-H str.); 3064, 3025 (m, C-H str. aromatic); 2930, 2851 (m, C-H str. aliphatic); 1605 (s, C=N str.); 1478 (m, C=C str.); 1448 (s, C-H bend.); 1094 (m); 1057 (m); 1009 (m);771 (s); 743 (m).

\subsection{X-ray structural analysis}

Single crystals of $\mathbf{1}$ were obtained by diffusion of diethyl ether into the methanol solution at room temperature. A suitable crystal was selected and used for data collection. The crystal was kept at $100.01 \mathrm{~K}$ during data collection. Diffraction data were measured on a Bruker PHOTO 100 area (Apex2 CCD) detector diffractometer with mirror optics monochromated Mo-K $\alpha$ radiation $(\lambda=0.71073 \AA$ ) generated from a microfocus $x$-ray sealed tube source. Data collection, cell refinement, and data reduction were performed by Brucker software. Multi-scan absorption correction was applied using SADABS-2014/5 software program. The structure was solved with ShelXT [16] structure solution program using intrinsic phasing and refined with the ShelXL [17] refinement package using Least Squares minimization. The hydrogen atoms were located geometrically and refined isotropically. Crystal data and details of structure determination are reported in Table1.

\section{$<$ Table1 $>$}




\section{Results and discussion}

\subsection{Preparation of samples}

The diamine ligand was synthesized by condensation of an equimolar solution of 1phenylmethaneamine and pyridine-2-carbaldehyde under reflux condition followed by reduction of the resulted Schiff base with sodium borohydride. The reaction of 1:1 molar ratio of the bidentate ligand and $\mathrm{CuX}_{2}(\mathrm{X}=\mathrm{Cl}$ or $\mathrm{Br})$ in methanol led to the formation of halo bridged dinuclear copper(II) complexes (Scheme 1).

\section{< Scheme 1 >}

\subsection{IR spectroscopy}

In the IR spectra of dinuclear complexes 1 and 2, several bands appear in the region 700-1600 $\mathrm{cm}^{-1}$ that are observed, although with minor shifts, in the spectra of the free ligand (Fig. S1 in the supplementary material). A comparison between IR spectra of ligand and complexes may provide invaluable evidence for the bonding patterns of the ligand to copper(II) ion. The band around $1050 \mathrm{~cm}^{-1}$ with medium intensity in the complexes is probably attributable to the stretching vibration of C-N bond [18]. The strong bands at 1440-1464 $\mathrm{cm}^{-1}$ are very likely related to the scissoring vibration of $-\mathrm{CH}_{2}$ - groups [18]. The band at around $750 \mathrm{~cm}^{-1}$ that appears in the spectrum of free ligand broader and is split in two in the region of 730-790 $\mathrm{cm}^{-1}$ may be owing to the rocking vibration of $\mathrm{CH}_{2}$ groups [18]. The stretching vibration of $\mathrm{N}_{-} \mathrm{CH}_{2}$ moiety in the free ligand, and the well-known bands in the region $2850 \pm 100 \mathrm{~cm}^{-1}$ that are accompanying with it are more important because they serve as an indication of coordination of the amine group of the ligand. Another evidence for the coordination of the amine group of the ligand to the copper(II) ion is the appearance of strong bands at 3175 and $3195 \mathrm{~cm}^{-1}$ in $\mathbf{1}$ and 2, respectively, associated with $\mathrm{NH}$ stretching vibration. This band appears at $3313 \mathrm{~cm}^{-1}$ and broader in the free ligand [18]. Upon covalent bond formation, these absorption bands evidently lose intensity, become shifted to the higher energy and merge with other $\mathrm{C}-\mathrm{H}$ absorption bands. A strong band at $1645 \mathrm{~cm}^{-1}$ in free ligand corresponds to the $\mathrm{C}=\mathrm{N}$ bond. This band appears in the complexes at 1607 and 1605 $\mathrm{cm}^{-1}$ in 1 and 2 respectively; the decreased values by $38-40 \mathrm{~cm}^{-1}$ confirm coordination of the pyridyl group of the ligand to the metal ion [19]. 


\subsection{X-ray crystallographic study}

Compound 1 crystallized in the monoclinic P21/c space group. The crystal structure along with coordination polyhedron of the compound is shown in Fig. 1 and the important bond lengths and angles are given in Table 2. Compound $\mathbf{1}$ is a dinuclear complex contains two identical copper ions with near square pyramidal geometry. Each copper ion is penta-coordinated by two nitrogen atoms from amine and pyridine moieties of bidentate ligand, one terminal chloride ion, and two bridging chloride atoms. The parameter $\tau$ [20] is calculated to be 0.22 ( $\tau=0$ for standard square pyramidal and $\tau=1$ for trigonal bipyramidal), which indicates the distorted square pyramidal geometry. The $\mathrm{Cu}-\mathrm{Cl}$ bond length for terminal $\mathrm{Cu}-\mathrm{Cl}(1)$ is 2.2494(4) $\AA$, while two bridging $\mathrm{Cu}-$ $\mathrm{Cl}(2)$ and $\mathrm{Cu}-\mathrm{Cl}(2 \mathrm{a})$ bond distances are 2.2766(3) $\AA$ and 2.7508(4) $\AA$, respectively. The unsymmetrical nature of the bridging chlorides is due to the geometrically difference in location of anions. One of the bridging chloride $(\mathrm{Cl}(2 \mathrm{a}))$ as well the nitrogen atoms and the terminal chloride ion are located in the basal plane and the other bridging chloride $(\mathrm{Cl}(2))$ occupies the apical position of the pyramid and has the longer band length. The geometry of the dimer contains two pyramids which share one base to apex edge, and their basal planes are parallel (Fig. 1b); this geometry is one of the known classes of configurations for di-copper complexes in which two chloride ions are doubly bridging between the metal centers [21, 22]. The $\mathrm{Cu}(\mu-$ $\left.\mathrm{Cl}_{2}\right) \mathrm{Cu}$ core has a symmetrical rhombic geometry with $\mathrm{Cu}-\mathrm{Cl}-\mathrm{Cu}$ angle of 83.089(11) ${ }^{\circ}$ and $\mathrm{Cl}-$ $\mathrm{Cu}-\mathrm{Cl}$ angle of $96.911(11)^{\circ}$ and $\mathrm{Cu} \cdots \mathrm{Cu}$ distance of 3.3530(3) $\AA$ which are rather smaller in compared with the reported values for related compounds [23, 24]. The bidentate ligand coordinates to the copper ion through the nitrogen atoms with bite angle of $81.73(5)^{\circ}$ and the bond distances of 2.0104(12) $\AA$ and 2.0274(11) $\AA$ for $\mathrm{Cu}-\mathrm{N}$ (pyridine) and $\mathrm{Cu}-\mathrm{N}($ amine), respectively. The benzyl rings are directed away from the $\mathrm{Cu}_{2} \mathrm{Cl}_{2}$ plane with an angle of $88.01^{\circ}$, and to opposite sides of terminal chloride ions to reduce the steric hindrance.

<Fig. 1>

$<$ Table 2>

\subsection{EPR study}

EPR spectra of compounds $\mathbf{1}$ and $\mathbf{2}$ were recorded at the X-band in frozen DMF solution at $80 \mathrm{~K}$ (Fig. 2). The spectral pattern is characteristic of copper(II) complexes with axial distortion and 
anisotropic hyperfine coupling. The calculated parameters from the EPR signals are $\mathrm{g}_{\|}=2.282$, and $A_{\|}=166 \times 10^{-4} \mathrm{~cm}^{-1}$ for $\mathbf{1}$ and $\mathrm{g}_{\|}=2.251$, and $\mathrm{A}_{\|}=171 \times 10^{-4} \mathrm{~cm}^{-1}$ for 2 . In both copper(II) complexes, the trend of $g_{\|}>g_{\perp}>g_{e}$ (2.003) suggest a square pyramidal structure with the unpaired electron located in the $d_{x^{2}-y^{2}}$ orbital and preclude the possibility of a trigonal bipyramidal geometry which would be expected to have $\mathrm{g}_{\perp}>\mathrm{g}_{\|}>\mathrm{g}_{\mathrm{e}}$ (2.003). The ratio of $f=\mathrm{g}_{\|}$ $\mathrm{A}_{\|}$has been suggested as an empirical index of distortion of donor set from planer toward tetrahedral. The value of $f$ varies from 105 to $135 \mathrm{~cm}$ for square planar complexes and that depends on the nature of the coordinated atoms. In the complexes with a tetrahedral distortion, this quotient increases noticeably to about 150-250 cm [25, 26]. The $f$ values of $137 \mathrm{~cm}$ and 131 $\mathrm{cm}$ in $\mathbf{1}$ and 2, respectively, indicate the square pyramidal geometry without tetrahedral distortion in the basal plane for both of the complexes.

EPR spectra of dinuclear complexes with two coupled copper(II) ions are expected to show the seven hyperfine features ( $2 n I+1 ; I=3 / 2$ and $n=2)$, and a half field signal attributed to the singlettriplet transition. In spite of the short $\mathrm{Cu} \cdots \mathrm{Cu}$ distance in the complexes, the spectra do not show characteristic signals of copper(II) dimers. It is most likely due to dissociation of dinuclear complexes and the formation of mononuclear species and/or existence of an equilibrium mixture with a higher percentage of monomer [27, 28]. The halo bridges are destroyed when the complexes solved in DMF and solvent molecules replaced the labile halide ligands. The additional humps that are observed in the spectra, especially for $\mathbf{2}$, possibly arise from dinuclear molecules exist in the equilibrium mixture.

\section{$<$ Fig. 2>}

\subsection{Thermal analysis}

Thermal gravimetric (TG) and differential thermal analysis (DTA) were carried out in a static argon atmosphere from 50 to $1000{ }^{\circ} \mathrm{C}$ to investigate the thermal behavior of the complexes. The DTA curve of complexes 1 and $\mathbf{2}$ (Fig. 3) exhibit an endothermic process without loss of weight at $210{ }^{\circ} \mathrm{C}$ and $184^{\circ} \mathrm{C}$ respectively, attributed to cleavage of bridging $\mathrm{Cu}-\mathrm{X}$ bands in $[\mathrm{LCu}(\mu-$ $\mathrm{X}) \mathrm{X}]_{2}(\mathrm{X}=\mathrm{Cl}, \mathrm{Br})$ and formation of mononuclear complexes[ $\left.\mathrm{LCuX}_{2}\right]$. The complexes begin to lose weight above $250^{\circ} \mathrm{C}$. Complex $\mathbf{1}$ loss $57.2 \%$ of its weight gradually in the range of 250- 
$560^{\circ} \mathrm{C}$ that is equivalent to the loss of the diamine ligands (calcd 59.6\%). The same decomposition occurred in complex 2 in the range of $250-435^{\circ} \mathrm{C}$ (observed $47.1 \%$; calcd $48.9 \%$ ). Further continues weight loss up to $1000^{\circ} \mathrm{C}$ may be attributed to the loss of organic moieties to leave copper(II) chloride (observed $40.5 \%$; calcd $40.7 \%$ for $\mathbf{1}$ ) and metallic copper for $\mathbf{2}$ (observed 15.5\%; calcd 15.07\%).

\section{$<$ Fig. 3 $>$}

\subsection{Chromotropism}

\subsubsection{Solvatochromism}

The complexes are soluble in a wide range of organic solvents and exhibit noticeable solvatochromic property. The origin of the color changes in the solutions is attributed to the shift in the d-d transition of the copper(II) ions as a result of interaction with solvents. The visible spectral changes in the studied solvents for compounds $\mathbf{1}$ and $\mathbf{2}$ are shown in Fig. 4. The locations of the $\lambda_{\max }$ values of the complexes along with the molar absorptivity values are collected in Table 3. The observed solvatochromism could be explained by the structural changes in different solvents. In low polar solvents such as dichloromethane, the electronic absorption spectra of the compounds are very similar to the related spectra in the solid state as shown in Fig. S2 in the supplementary material. It could be due to the solvation of compounds with minimal changes in the structure. Therefore, the dimeric structure of complexes is preserved in the low polar solvents (Route 1 in scheme 2), while the solvation of the neutral monomers produced from cleavage of weak $\mathrm{Cu}-\mathrm{X}$ bridging bands cannot be excluded. In the solvents with moderate polarity such as $\mathrm{MeOH}$, DMSO and DMF both complexes display almost a single unsymmetrical broad d-d band in the region 700-800 nm and strong charge transfer bands with shoulders at 330 and $380 \mathrm{~nm}$ for $\mathbf{1}$ and $\mathbf{2}$, respectively owing to the halide ligand-to-metal charge-transfer (LMCT) transitions of coordinated halide [29]. The former band is characteristic of an unsymmetrical geometric structure due to ligand field and Jahn-Teller effects around the copper(II) ions. Generally, this band is assigned to the overlapping transitions $\mathrm{d}_{\mathrm{xz}} / \mathrm{d}_{\mathrm{yz}} \rightarrow \mathrm{d}_{\mathrm{x}^{2}-\mathrm{y}^{2}}$, $d_{x y} \rightarrow d_{x^{2}-y^{2}}$, and $d_{z^{2}} \rightarrow d_{x^{2}-y^{2}}$. This may result in a mononuclear complex [CuLX(solv) 3 ] X ( $\mathrm{X}=\mathrm{Cl}$ or $\mathrm{Br}$ ) (Route 2 in scheme 2). This proposed mechanism is further confirmed by increasing the molar conductance values of the complexes in the polar solvents as shown in 
Table 4. In aqueous solution, both complexes turn blue and their absorption spectra are also similar (Fig. S3 in supplementary material). This point to that in aqueous solution complex $\mathbf{1}$ behaves like 2. Both of the complexes exhibit a very broad and weak band centered at $680 \mathrm{~nm}$ (d-d band) and strong charge transfer band at $260 \mathrm{~nm}$ (Route 3 in Scheme 2). This may occur if the $\mathrm{Cu}-\mathrm{X}$ bond is broken by water molecules and formation of $\left[\mathrm{CuL}(\mathrm{solv})_{4}\right] \mathrm{X}_{2}$ complex. This structural change is along with an increase in the molar conductance values of complexes in the aqueous solution as shown in Table 4.

\section{$<$ Scheme 2>}

$<$ Table 3>

$<$ Table 4>

$<$ Fig. 4>

\subsubsection{Halochromism}

The electronic spectra of the aqueous solution of the compounds $\mathbf{1}$ and $\mathbf{2}$ are sensitive to $\mathrm{pH}$. When the dinuclear complexes are dissolved in water, dissociation of the halide ions and hydration of the compound led to the mononuclear complex as shown in scheme 2 . This phenomenon occurred in both compounds. As a result, the aqueous solution of two compounds has identical electronic spectra. The sky-blue color of the aqueous solution turned to purple by addition of a base ( $\mathrm{NaOH} 0.1 \mathrm{M}$ ) that reversibly reappearance to its original color by addition of an acid $\left(\mathrm{HClO}_{4} 0.1 \mathrm{M}\right)$. The visible spectral changes for the compound upon increasing the $\mathrm{pH}$ of the solution from 5.4 (the origin $\mathrm{pH}$ ) to 10.5 are illustrated in Fig. 5. The blue shift in the absorption maxima is along with an isosbestic point at $662 \mathrm{~nm}$ which is possibly due to deprotonation of the amine group in an alkaline medium as shown in scheme 3 . This mechanism is evidenced by spectrophotometric titration of the complexes with sodium hydroxide (0.1 M) which showed consumption of two equivalents hydroxide anions in the $\mathrm{pH}$ range of 5.4-10.5 (insert of Fig.5). In the other hand, upon addition of the acid $\left(\mathrm{HClO}_{4} 0.1 \mathrm{M}\right)$, the blue color of the solution was gradually diminished. This process was reversible so that, the original blue color redeveloped by increasing the $\mathrm{pH}$ of the solution to around 5.4 with the addition of a base $(\mathrm{NaOH}$ 
0.1 M). The electronic absorption spectra of the compound (Fig. 6) shows a decreasing in the intensity of $\mathrm{d}$ - $\mathrm{d}$ band accompanied with a redshift upon lowering the $\mathrm{pH}$ to around 2 by adding an acid $\left(\mathrm{HClO}_{4} 0.1 \mathrm{M}\right)$. Spectrophotometric titration of the complexes with perchloric acid demonstrated that decolorization occurred with consumption of four equivalents protons (inset of Fig. 6). It is probably attributed to protonation of pyridyl and amine groups and formation of a totally hydrated copper(II) complex (scheme 3). This phenomenon was confirmed by comparison of the acidified spectrum with the spectra of the ligand and copper (II) halide in acidic solution.

<Fig. 5>

$<$ Fig. 6>

< Scheme 3>

\subsubsection{Thermochromism}

The compounds show reversible thermochromism in solvents with high boiling points such as DMF and DMSO. The effect of temperature on the visible spectra of compound 1 was studied over a temperature range of $21-170{ }^{\circ} \mathrm{C}$ in DMSO (Fig. 7). By heating the solution up to $90{ }^{\circ} \mathrm{C}$ the original blue color changed to green and further increasing the temperature up to $170^{\circ} \mathrm{C}$ became brown. It was presumably associated with gradual substitution of the chloride anions and the chelating ligand by solvent molecules. The observed brown color is attributed to the presence of free chelating ligand and $\left[\mathrm{Cu}(\mathrm{dmso})_{n}\right] \mathrm{Cl}_{2}$ in the solution. This phenomenon is totally reversible. However due to the strong bond formed between copper(II) ion and DMSO molecules and the presence of a copious amount of solvent molecules around the metal center, the reverse reaction is slow, and it takes about 5 days to the full development of the original color. The same thermochromism behavior was observed in compound $\mathbf{2}$ in the solvent of DMSO.

<Fig. 7>

\section{Conclusion}

Two new dinuclear copper(II) complexes in which, two metal centers connected with doubly chloride or bromide bridge were synthesized and fully characterized. The complexes have distorted square pyramidal geometries where, the axial sites of the copper(II) ions are occupied 
by the bridging halides that equatorially coordinated to the other copper ion, forming dimeric copper(II) complexes. The bridged halide ions can be easily replaced by solvent molecules due to their weak coordination to copper(II) centers. The complexes are soluble in water and common organic solvents and exhibited solvatochromism behavior. The origin of this phenomenon is structural changes followed by solvation in solvents with different polarities. The complexes are halochromic and show different colors in $\mathrm{pH}$ range 2-10.5 due to protonation and deprotonation of coordinated ligands in aqueous solutions. Moreover, the compounds displayed reversible thermochromism with obvious color changes in the solvents of DMSO and DMF through the temperature range $21-170{ }^{\circ} \mathrm{C}$. The mechanism for this reversible color change is likely dissociation of the coordinated halides at elevated temperature and their re-coordination at room temperature. The observed color changes in both complexes are approximately in the same range. However since the compound $\mathbf{2}$ is more soluble in the studied solvents, it can be a better chromotropic probe. This study will be of value with regard to complexes which find their application as possible candidates for molecular switches and sensor materials.

\section{Supplementary data:}

CCDC 1903681 contains the supplementary crystallographic data for this paper. These data can be obtained free of charge via www.ccdc.cam.ac.uk/conts/retrieving.html or from the Cambridge Crystallographic Data Centre, 12, Union Road, Cambridge CB2 1EZ, UK; fax: (+44) 1223 336033; or e-mail: deposit@ccdc.cam.ac.uk. Supporting Information.

\section{Acknowledgement}

We are grateful for the financial support of university of Mazandaran of the Islamic Republic of Iran.

\section{References}

[1] W. Linert, Y. Fukuda, A. Camard, Chromotropism of coordination compounds and its applications in solution, Coord. Chem. Rev. 218 (2001) 113-152.

[2] O. Sato, Optically Switchable Molecular Solids: Photoinduced Spin-Crossover, Photochromism, and Photoinduced Magnetization, Acc. Chem. Res 36(9) (2003) 692-700. 
[3] B. Narayanan, M.M. Bhadbhade, Structural studies on $\mathrm{Cu}(\mathrm{N}, \mathrm{N} \text {-dialkyldiamine })_{2} \mathrm{X}_{2}$ complexes: X-ray structure of bis(N-isopropyl-1,2-ethanediamine) copper(II)tetrafluroborate, J. Mol. Struct. 516(2) (2000) 247-254.

[4] W. Linert, R.F. Jameson, A. Taha, Donor numbers of anions in solution: the use of solvatochromic Lewis acid-base indicators, J. Chem. Soc., Dalton Trans. (21) (1993) 31813186.

[5] K. Sone, Y. Fukuda, Solvatochromism of transition metal complexes with organic ligands in donor and acceptor solvents, Rev.Inorg. Chem. 11(2-4) (1990) 123-153.

[6] H. Icbudak, E. Adiyaman, N. Cetin, A. Bulut, O. Buyukgungor, Synthesis, structural characterization and chromotropism of a Ni (II) and a Co (II) compound with acesulfamate as a ligand, Transition Met. Chem. 31(5) (2006) 666-672.

[7] C.-T. Chen, S.-Y. Liao, K.-J. Lin, C.-H. Chen, T.-Y.J. Lin, Structural effects on molecular dipoles and solvatochromism of Nickel(diimine)(dithiolate) complexes, Inorg. Chem. 38(11) (1999) 2734-2741.

[8] N. Shintani, E. Nukui, H. Miyamae, Y. Fukuda, K. Sone, Studies on Mixed Chelates. XXII. Five-Coordinate Copper (II) Chelates with N, N, N', N ", N "-Pentamethyldiethylenetriamine and $\beta$-Diketonates, Bull. Chem. Soc. Jpn. 67(7) (1994) 1828-1834.

[9] A. Taha, A. Farag, A. Ammar, H. Ahmed, Structural, molecular orbital and optical characterizations of binuclear mixed ligand copper (II) complex of phthalate with $\mathrm{N}, \mathrm{N}, \mathrm{N}^{\prime}$, N'-tetramethylethylenediamine and its applications, Spectrochim. Acta, Part A 130 (2014) 494-501.

[10] H. Golchoubian, R. Samimi, Solvato- and thermochromism study in oxalato-bridged dinuclear copper(II) complexes of bidentate diamine ligands, Polyhedron 128 (2017) 68-75.

[11] H. Golchoubian, S. Nateghi, Chromotropism in halo-bridged dimers. Structural characterization of bis ( $\mu$-halo) bis (halo $\mathrm{N}$-(pyridin-2-ylmethyl) cyclohexanamine copper (II)), J. Coord. Chem. 69(21) (2016) 3192-3205.

[12] R. Nazari, H. Golchoubian, G. Bruno, Mononuclear copper (II) complexes containing chelating ligand of 2-methyl-N-(pyridine-2-yl-methyl) propane-2-amine as chromotropic probes, J. Iran. Chem. Soc. 16(5) (2019) 1041-1052. 
[13] F. Murata, M. Arakawa, A. Nakao, K. Satoh, Y. Fukuda, Syntheses, crystal structures and chromotropic properties of Nickel (II) mixed ligand complexes containing N-methyl-1, 4diazacycloheptane and various $\beta$-diketonates, Polyhedron 26(8) (2007) 1570-1578.

[14] R. Nazari, H. Golchoubian, G. Bruno, Chromotropism studies on copper (II) compounds. Part II. Dinuclear copper (II) complexes with triply-bridged hydroxo, acetate, and halo ligands, J. Coord. Chem. 71(16-18) (2018) 2510-2525.

[15] I. Lumb, M.S. Hundal, M. Corbella, V. Gómez, G. Hundal, Copper (II) Complexes of N, NDiisopropylpicolinamide-Solvatochromic and Thermochromic Phase Change of a Monomeric Complex to a Ferromagnetically Coupled Dimeric Complex, Eur. J. Inorg. Chem. 2013(27) (2013) 4799-4811.

[16] G.M. Sheldrick, SHELXT-Integrated space-group and crystal-structure determination, Acta Cryst. A 71(1) (2015) 3-8.

[17] G.M. Sheldrick, Crystal structure refinement with SHELXL, Acta Cryst. C 71(1) (2015) 38.

[18] C. Tsiamis, M. Themeli, Substituent and solvent effects in the spectra and structure of some mixed-ligand copper (II) chelates containing $\beta$-ketoenols, Inorg. Chim. Acta 206(1) (1993) 105-115.

[19] F. Yraola, F. Albericio, M. Corbella, M. Royo, [\{Cu(pzPh)(Opo $\left.)\}_{2}(\mu-\mathrm{Cl})_{2}\right]$ : A new dinuclear copper(II) complex with a chloride bridge and mixed blocking ligands, Inorg. Chim. Acta 361(8) (2008) 2455-2461.

[20] A.W. Addison, T.N. Rao, J. Reedijk, J. van Rijn, G.C. Verschoor, Synthesis, structure, and spectroscopic properties of copper (II) compounds containing nitrogen-sulphur donor ligands; the crystal and molecular structure of aqua [1, 7-bis (N-methylbenzimidazol-2'-yl)-2, 6-dithiaheptane] copper (II) perchlorate, J. Chem. Soc., Dalton Trans. (7) (1984) 1349-1356.

[21] A. Rodríguez-Fortea, P. Alemany, S. Alvarez, E. Ruiz, Exchange coupling in halo-bridged dinuclear Cu (II) compounds: A density functional study, Inorg. Chem. 41(14) (2002) 37693778.

[22] M. Rodríguez, A. Llobet, M. Corbella, A.E. Martell, J. Reibenspies, Synthesis, structure, and magnetic properties of a new chloro-bridged dimer $\left[\mathrm{Cu}_{2}(\mathrm{dpt})_{2} \mathrm{Cl}_{2}\right] \mathrm{Cl}_{2}$ with an unusual structure and ferromagnetic coupling, Inorg. Chem. 38(10) (1999) 2328-2334. 
[23] A.M. Schuitema, A.F. Stassen, W.L. Driessen, J. Reedijk, Synthesis, magnetic properties, and crystal structure of dinuclear antiferromagnetic [ $\mathrm{Cu}_{2}$ (5-aminomethyl-3-methylpyrazole) ${ }_{2} \mathrm{Cl}_{4}$ ], Inorg. Chim. Acta 337 (2002) 48-52.

[24] J. Cho, M.K. Chun, S. Nayab, J.H. Jeong, Synthesis and structures of copper (II) complexes containing $\mathrm{N}$, N-bidentate $\mathrm{N}$-substituted phenylethanamine derivatives as pre-catalysts for heterotactic-enriched polylactide, Polyhedron 163 (2019) 54-62.

[25] U. Sakaguchi, A.W. Addison, Spectroscopic and redox studies of some copper(II) complexes with biomimetic donor atoms: implications for protein copper centres, J. Chem. Soc., Dalton Trans. (4) (1979) 600-608.

[26] J. Losada, I. del Peso, L. Beyer, Electrochemical and spectroelectrochemical properties of copper(II) Schiff-base complexes, Inorg. Chim. Acta 321(1) (2001) 107-115.

[27] E. Manoj, M.R.P. Kurup, A. Punnoose, Preparation, magnetic and EPR spectral studies of copper(II) complexes of an anticancer drug analogue, Spectrochim. Acta, Part A 72(3) (2009) 474-483.

[28] S. Thakurta, P. Roy, G. Rosair, C.J. Gómez-García, E. Garribba, S. Mitra, Ferromagnetic exchange coupling in a new bis( $\mu$-chloro)-bridged copper(II) Schiff base complex: Synthesis, structure, magnetic properties and catalytic oxidation of cycloalkanes, Polyhedron 28(4) (2009) 695-702.

[29] A.B.P. Lever, Inorganic electronic spectroscopy, 2nd ed., Elsevier, Amsterdam, 1984, p. 356. 


\section{Captions for Figures}

Fig. 1. (a) ORTEP view with atom labeling scheme and (b) coordination polyhedron for complex 1.

Fig. 2. EPR spectra of complexes 1 and 2 in DMF at 80K. The vertical bar locates $g_{e}=2.003$.

Fig. 3. TG-DTA curves of complexes 1 and 2.

Fig. 4. Absorption spectra of complexes 1 and 2 in different solvents.

Fig. 5. The $\mathrm{pH}$ titration of 1 with $\mathrm{NaOH}(0.1 \mathrm{M})$ in the $\mathrm{pH}$ range of 5.4-10.5.

Fig. 6. The $\mathrm{pH}$ titration of 1 with $\mathrm{HCl}(0.1 \mathrm{M})$ in the $\mathrm{pH}$ range of 5.4-2.

Fig. 7. Temperature dependence of the visible absorbance of the complexes in DMSO. 
Fig. 1.

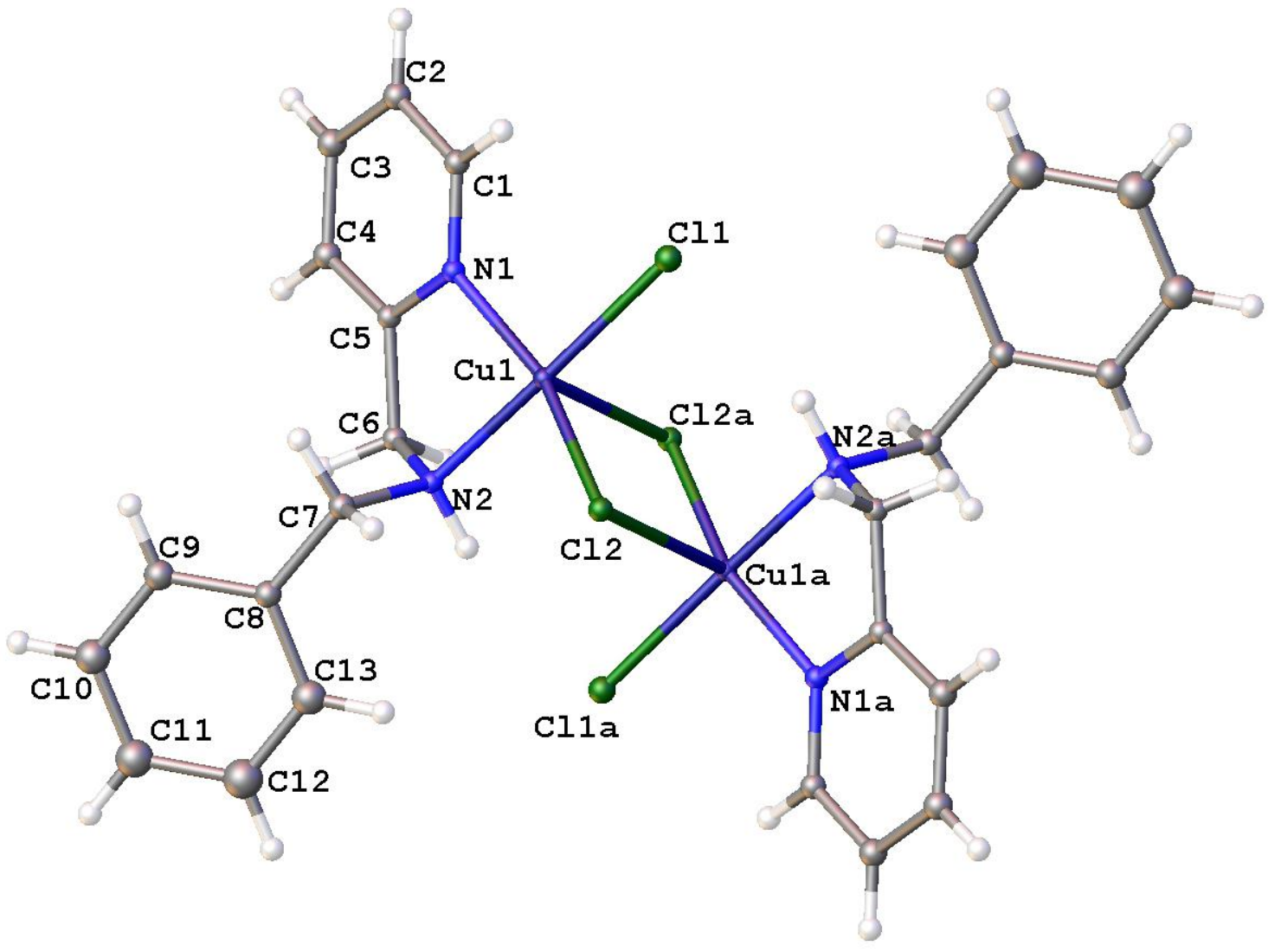

(a)

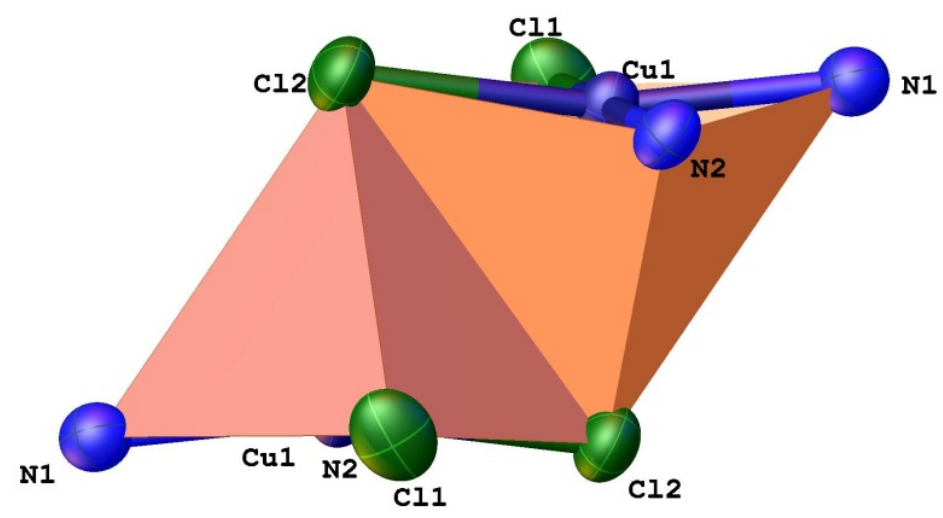

(b) 
Fig. 2.

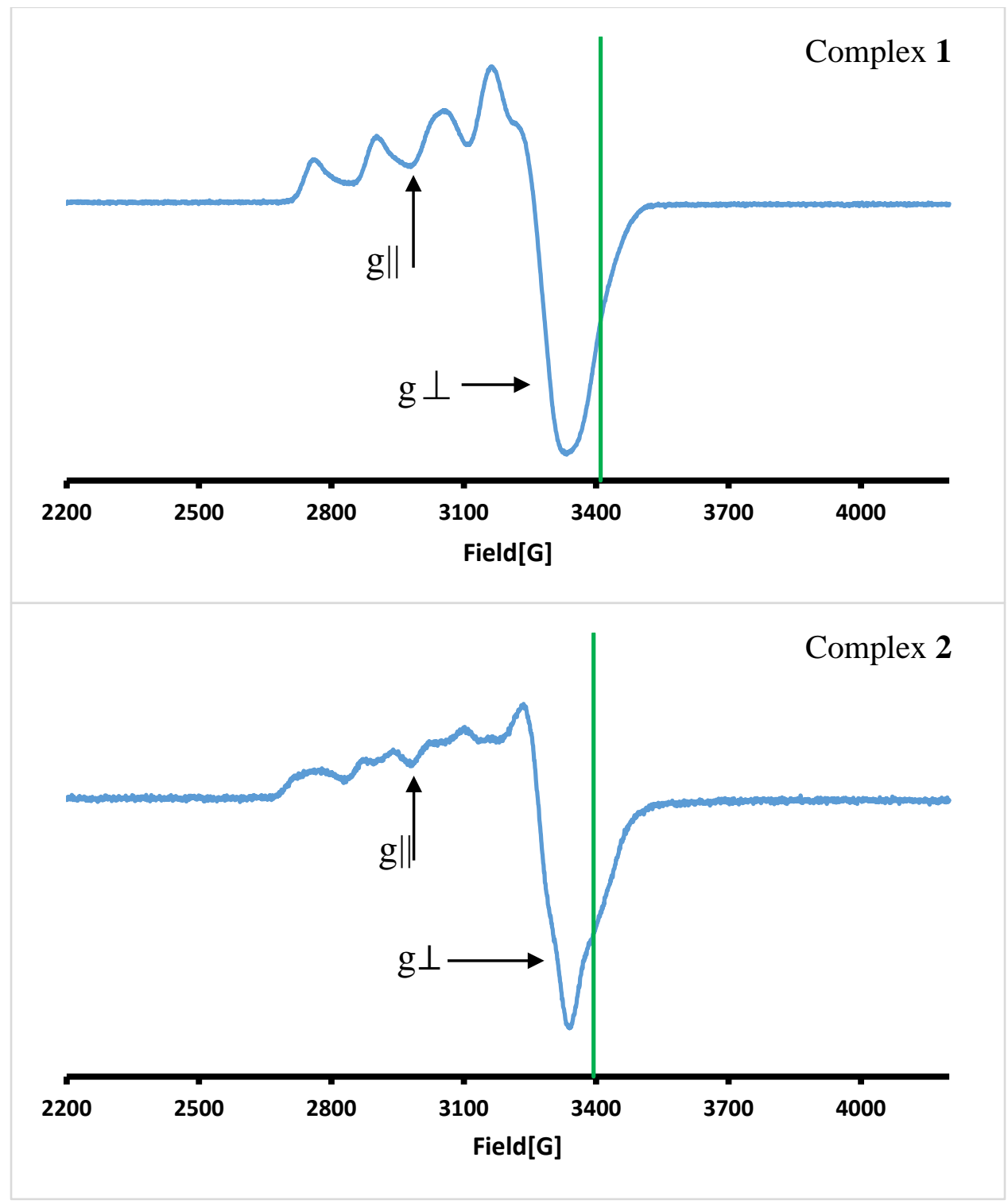


Fig. 3.
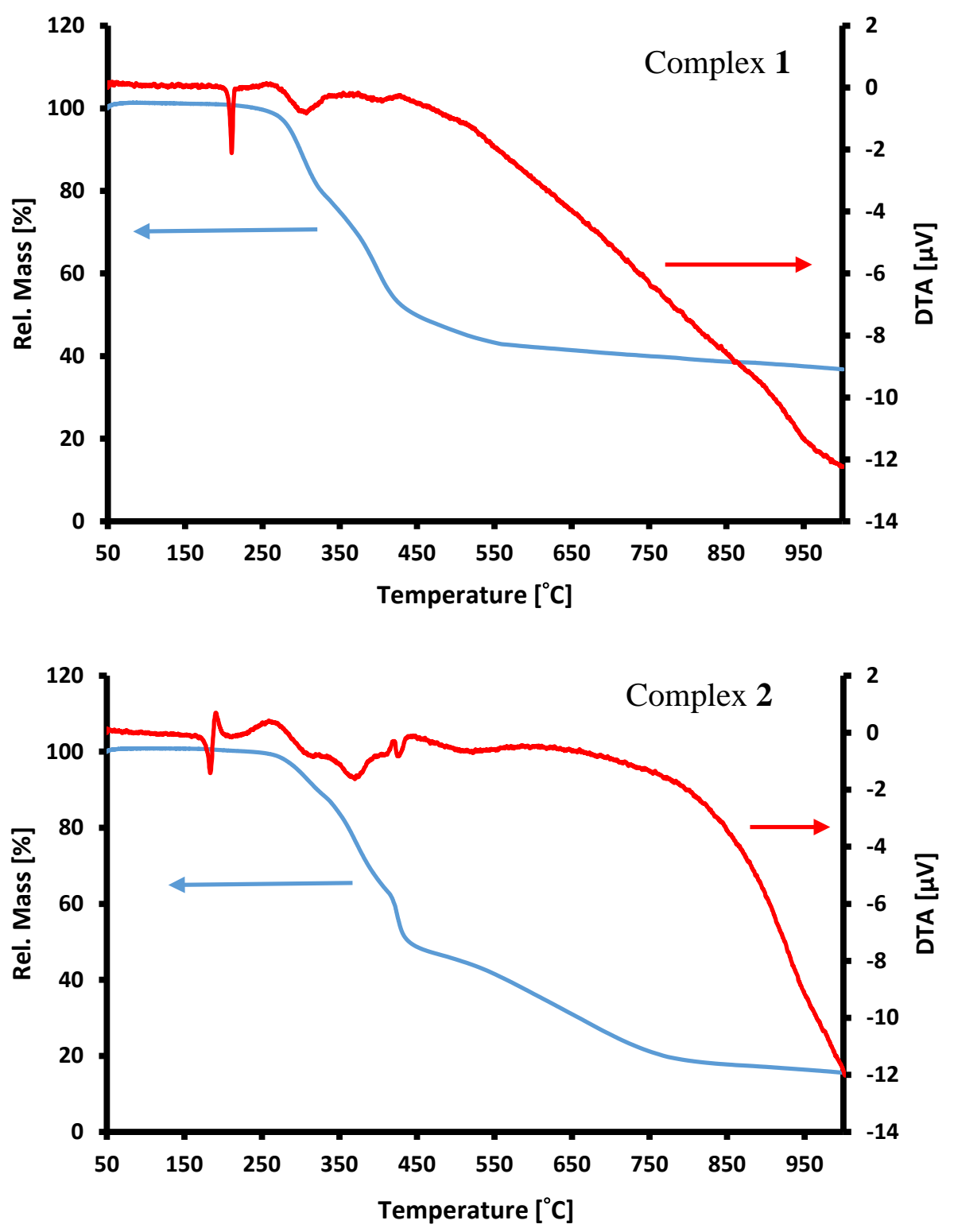
Fig. 4.
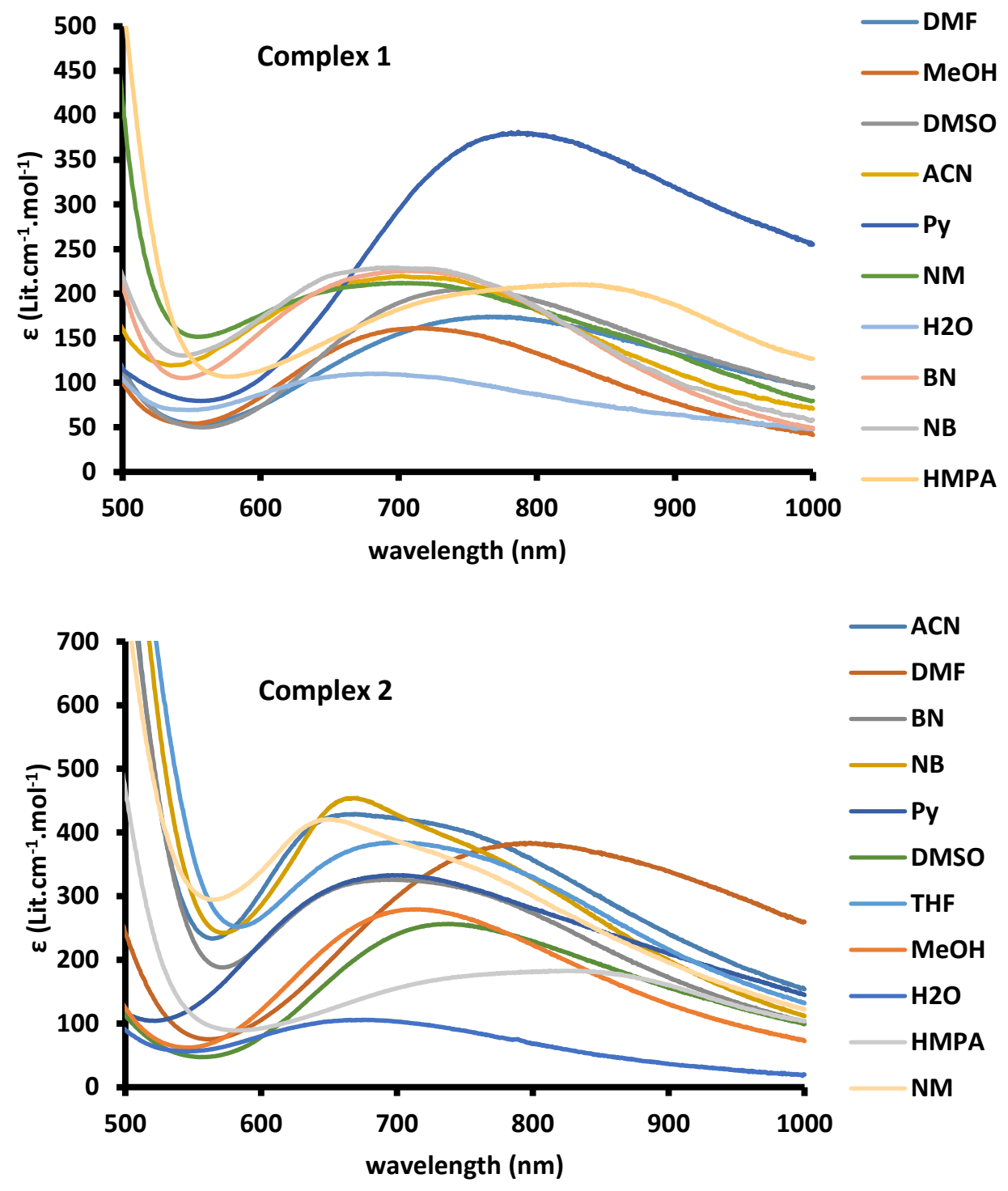
Fig. 5.

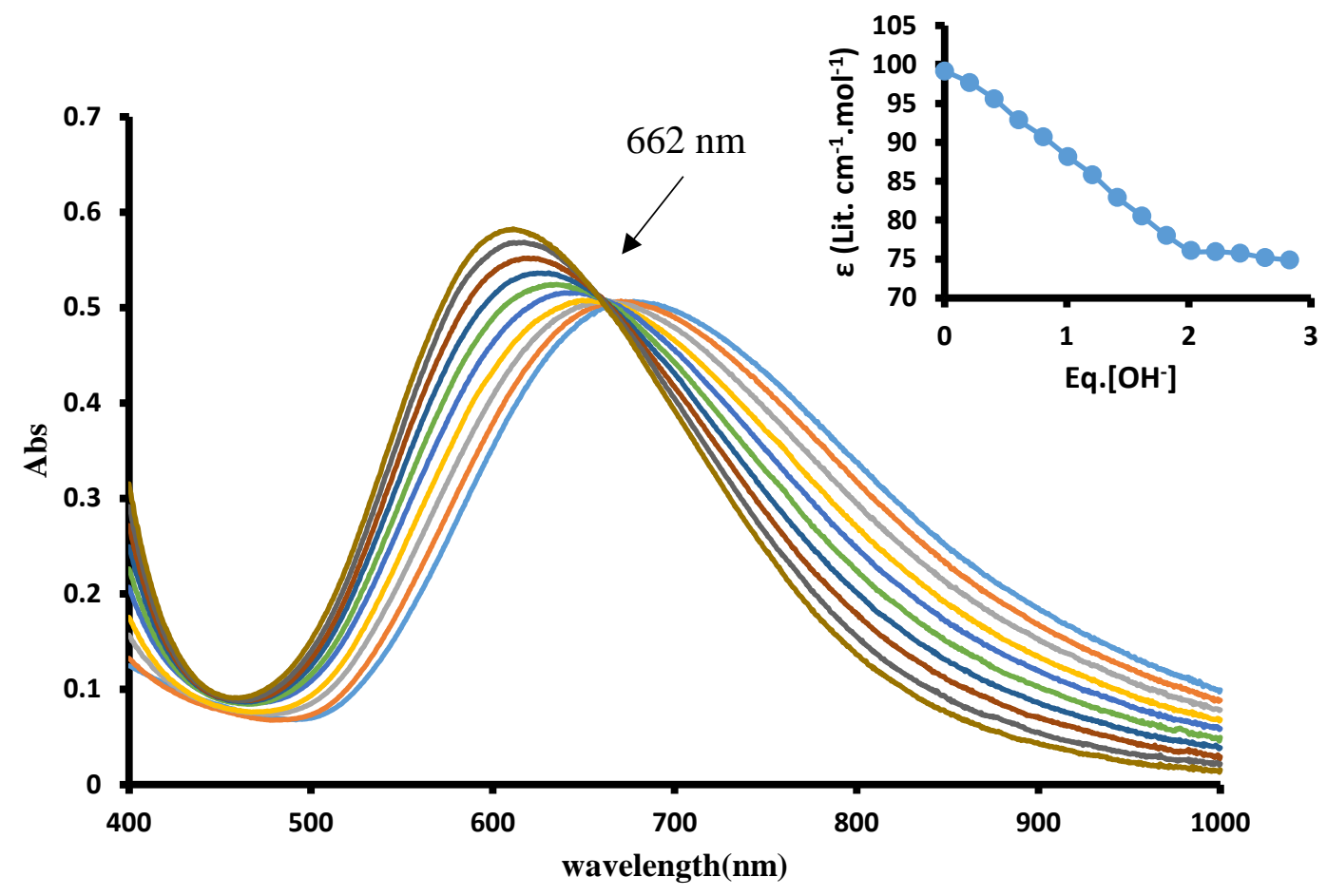


Fig. 6.

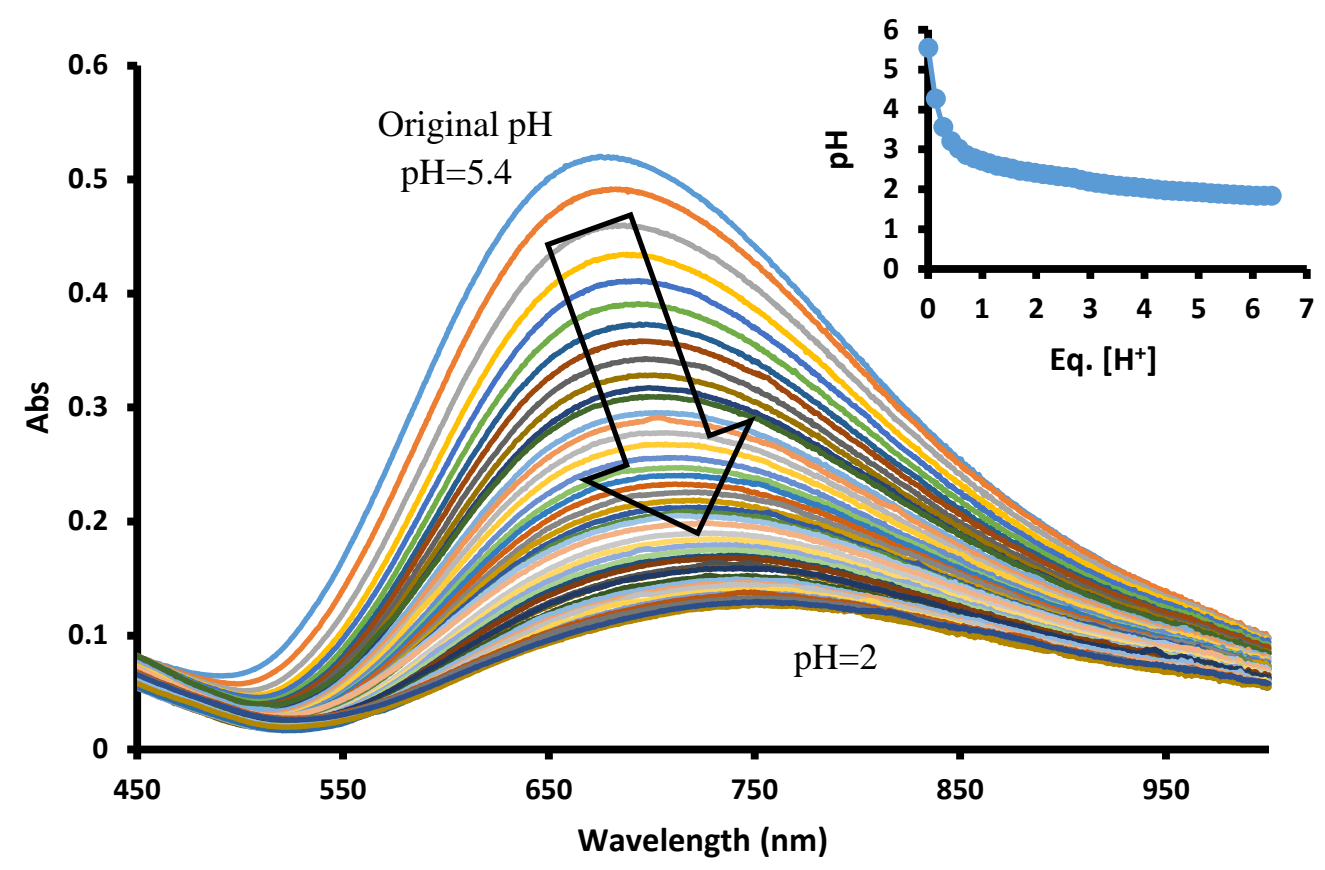


Fig. 7.
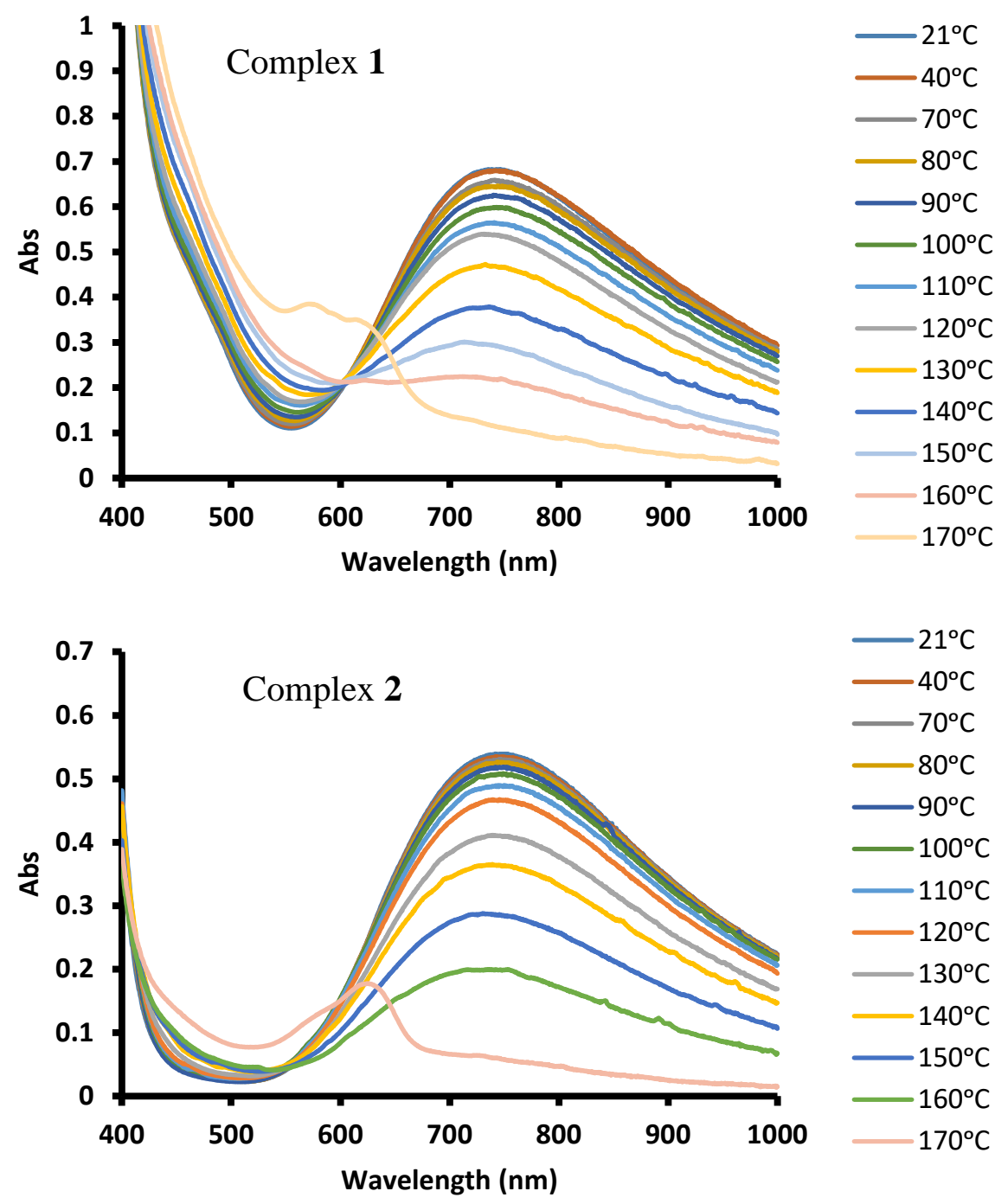

$-21^{\circ} \mathrm{C}$

$-40^{\circ} \mathrm{C}$

$-70^{\circ} \mathrm{C}$

$-80^{\circ} \mathrm{C}$

$-90^{\circ} \mathrm{C}$

$-100^{\circ} \mathrm{C}$

$-110^{\circ} \mathrm{C}$

$-120^{\circ} \mathrm{C}$

$-130^{\circ} \mathrm{C}$

$-140^{\circ} \mathrm{C}$

$-150^{\circ} \mathrm{C}$

$-160^{\circ} \mathrm{C}$

$-170^{\circ} \mathrm{C}$ 
Caption for Schemes

Scheme 1. Synthetic outline for preparation of ligand and complexes.

Scheme 2. Proposed structural change of the complexes in solvents with different polarities.

Scheme 3. Proposed interconversion of complexes caused by acid and base (pH 2-10.5) in aqueous solution. 
Scheme 1

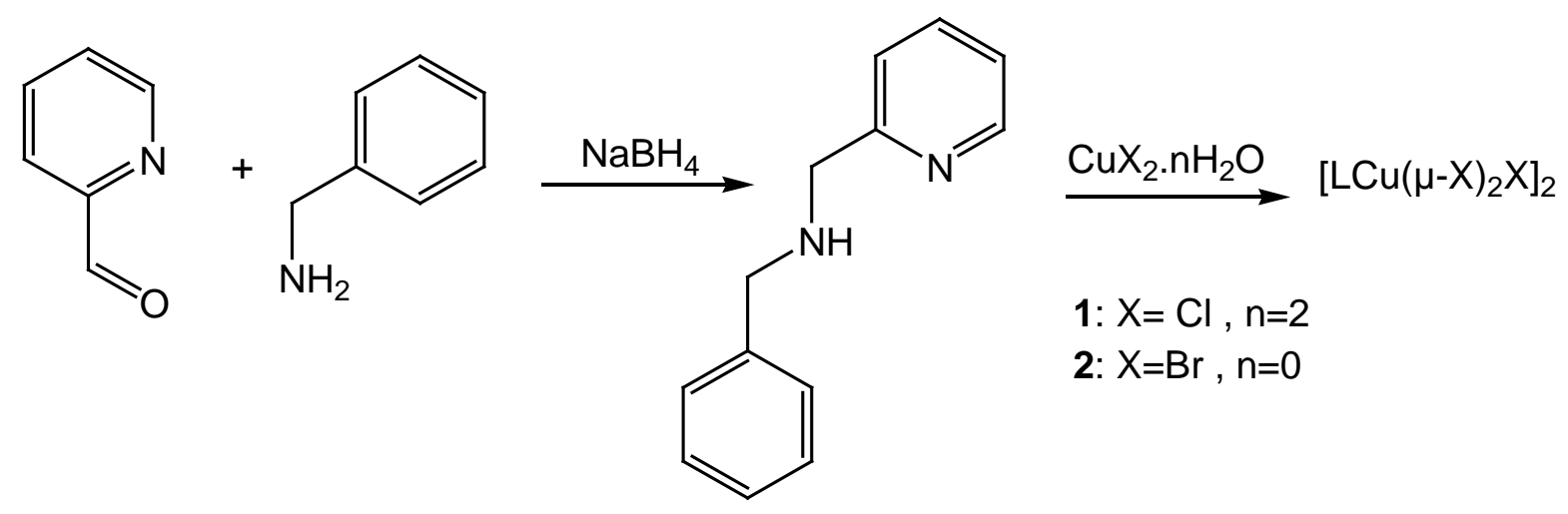




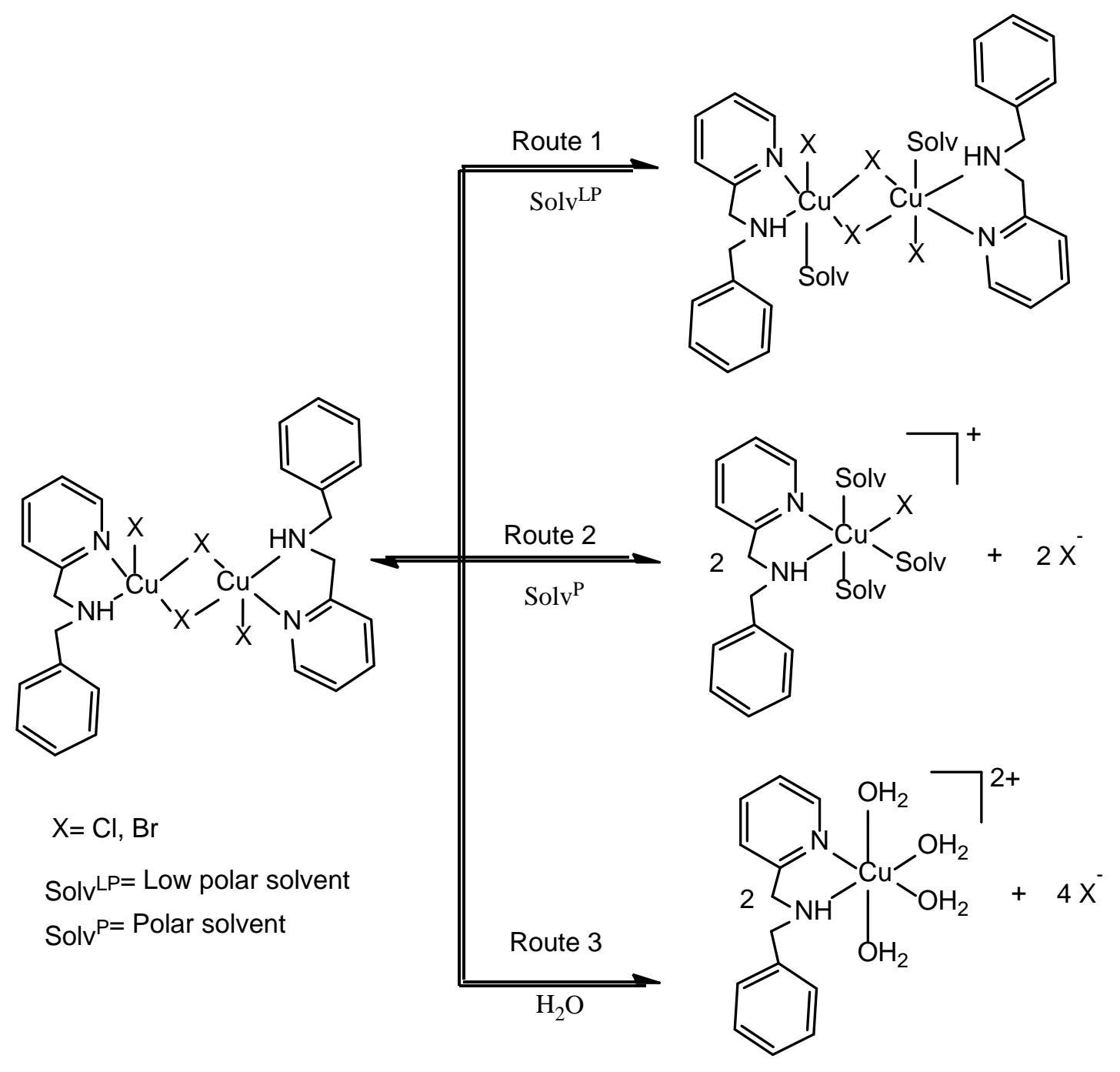


Scheme 3

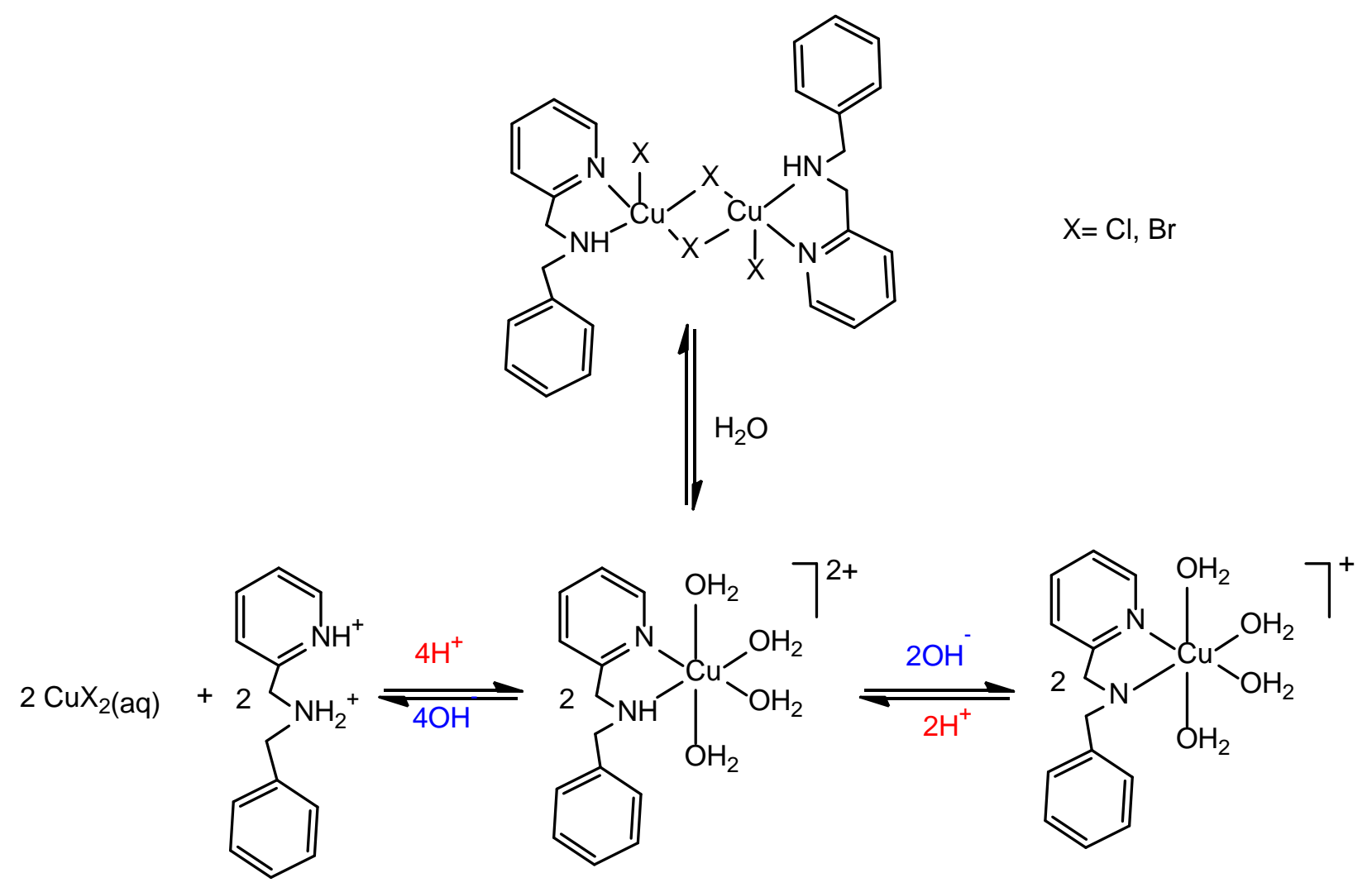


able 1. Crystal data and structure refinement for $\mathbf{1}$.

\begin{tabular}{|c|c|}
\hline Empirical formula & $\mathrm{C}_{26} \mathrm{H}_{28} \mathrm{Cl}_{4} \mathrm{Cu}_{2} \mathrm{~N}_{4}$ \\
\hline Formula weight & 665.40 \\
\hline Color & Blue \\
\hline Temperature (K) & $100(2)$ \\
\hline Wavelength $(\AA)$ & 0.71073 \\
\hline Crystal system & Monoclinic \\
\hline Space group & $\mathrm{P} 2{ }_{1} / \mathrm{c}$ \\
\hline \multicolumn{2}{|l|}{ Unit cell dimensions } \\
\hline $\mathrm{a}(\AA)$ & $10.9434(5)$ \\
\hline $\mathrm{b}(\AA)$ & $12.8949(5)$ \\
\hline c $(\AA)$ & $10.0913(4)$ \\
\hline$\beta\left(^{\circ}\right)$ & $98.6020(10)$ \\
\hline Volume $\left(\AA^{3}\right)$ & 1408.01(10) \\
\hline Z & 2 \\
\hline Calculated density $\left(\mathrm{g} \mathrm{cm}^{-3}\right)$ & 1.569 \\
\hline$\mu\left(\mathrm{mm}^{-1}\right)$ & 1.913 \\
\hline $\mathrm{F}\left(\begin{array}{lll}0 & 0 & 0\end{array}\right)$ & 676.0 \\
\hline Crystal size $\left(\mathrm{mm}^{3}\right)$ & $0.5 \times 0.3 \times 0.2$ \\
\hline$\theta$ range for data collection $\left({ }^{\circ}\right)$ & $2.46-27.49$ \\
\hline \multirow[t]{3}{*}{ Index ranges } & $-14 \leq \mathrm{h} \leq 14$ \\
\hline & $-16 \leq \mathrm{k} \leq 16$ \\
\hline & $-12 \leq 1 \leq 13$ \\
\hline Reflections collected/unique( $\left.\mathrm{R}_{\text {int }}\right)$ & $50161 / 3235(0.0442)$ \\
\hline Completeness to $\theta=27.522$ & $99.9 \%$ \\
\hline Refinement method & Full matrix least-squares on $\mathrm{F}^{2}$ \\
\hline Data/restraints/parameters & $3235 / 0 / 163$ \\
\hline Final $R$ indices $[\mathrm{I}>2 \sigma(\mathrm{I})]$ & $\mathrm{R}_{1}=0.0209, \mathrm{wR}_{2}=0.0519$ \\
\hline $\mathrm{R}$ indices (all data) & $\mathrm{R}_{1}=0.0225, \mathrm{wR}_{2}=0.0527$ \\
\hline Goodness-of-fit on $\mathrm{F}^{2}$ & 1.082 \\
\hline Largest diff. peak and hole (e $\AA^{-3}$ ) & 0.39 and -0.63 \\
\hline
\end{tabular}


Table 2. Selected bond lengths $(\AA)$ and angles $\left({ }^{\circ}\right)$ for $\mathbf{1}$.

\begin{tabular}{llll}
\hline Bond distances & & & \\
$\mathrm{Cu}(1)-\mathrm{N}(1)$ & $2.0104(12)$ & $\mathrm{Cu}(1)-\mathrm{Cl}(1)$ & $2.2494(4)$ \\
$\mathrm{Cu}(1)-\mathrm{N}(2)$ & $2.0274(11)$ & $\mathrm{Cu}(1)-\mathrm{Cl}(2)$ & $2.2766(3)$ \\
$\mathrm{Cu}(1)-\mathrm{Cl}(2 \mathrm{a})$ & $2.7508(4)$ & $\mathrm{Cl}(2)-\mathrm{Cl}(2 \mathrm{a})$ & $3.7759(4)$ \\
$\mathrm{Cu}(1)-\mathrm{Cu}(1 \mathrm{a})$ & $3.3530(3)$ & & \\
Bond angles & & & \\
$\mathrm{N}(1)-\mathrm{Cu}(1)-\mathrm{N}(2)$ & $81.73(5)$ & $\mathrm{N}(1)-\mathrm{Cu}(1)-\mathrm{Cl}(2)$ & $163.71(3)$ \\
$\mathrm{N}(1)-\mathrm{Cu}(1)-\mathrm{Cl}(1)$ & $96.10(3)$ & $\mathrm{N}(1)-\mathrm{Cu}(1)-\mathrm{Cl}(2 \mathrm{a})$ & $95.94(3)$ \\
$\mathrm{N}(2)-\mathrm{Cu}(1)-\mathrm{Cl}(1)$ & $177.14(3)$ & $\mathrm{N}(2)-\mathrm{Cu}(1)-\mathrm{Cl}(2 \mathrm{a})$ & $86.17(3)$ \\
$\mathrm{N}(2)-\mathrm{Cu}(1)-\mathrm{Cl}(2)$ & $89.18(3)$ & $\mathrm{Cl}(1)-\mathrm{Cu}(1)-\mathrm{Cl}(2)$ & $93.360(13)$ \\
$\mathrm{Cl}(1)-\mathrm{Cu}(1)-\mathrm{Cl}(2 \mathrm{a})$ & $92.216(13)$ & $\mathrm{Cl}(2)-\mathrm{Cu}(1)-\mathrm{Cl}(2 \mathrm{a})$ & $96.911(11)$ \\
$\mathrm{Cu}(1)-\mathrm{Cl}(2)-\mathrm{Cu}(1 \mathrm{a})$ & $83.089(11)$ & & \\
\hline a. $2-\mathrm{X}, 1-\mathrm{Y}, 2-\mathrm{Z}$ & & &
\end{tabular}


Table 3. The electronic absorption maxima of $\mathbf{1}$ and $\mathbf{2}$ in different solvents.

\begin{tabular}{lllll}
\hline & \multicolumn{3}{c}{ Compound $\mathbf{~}$} & Compound 2 \\
\cline { 2 - 5 } Solvent & $\lambda_{\max }(\mathrm{nm})$ & $\varepsilon\left(\mathrm{L} \mathrm{cm}^{-1} \mathrm{~mol}^{-1}\right)$ & $\lambda_{\max }(\mathrm{nm})$ & $\varepsilon\left(\mathrm{L} \mathrm{cm}^{-1} \mathrm{~mol}^{-1}\right)$ \\
\hline BN & 709 & 225 & 690 & 326 \\
Py & 786 & 381 & 704 & 333 \\
DMSO & 750 & 205 & 737 & 257 \\
NB & 695 & 299 & 670 & 455 \\
MeOH & 710 & 161 & 714 & 279 \\
HMPA & 831 & 211 & 812 & 183 \\
NM & 692 & 212 & 649 & 421 \\
DMF & 763 & 174 & 798 & 384 \\
$\mathrm{H}_{2} \mathrm{O}$ & 689 & 110 & 674 & 106 \\
ACN & 706 & 213 & 671 & 429 \\
DCM & 683 & 188 & 670 & 546 \\
\hline
\end{tabular}


Table 4. Molar conductivities data $\left(\Lambda_{\mathrm{m}}\right)$ of $\mathbf{1}$ and $2\left(\Omega^{-1} \mathrm{~cm}^{2} \mathrm{~mol}^{-1}\right)$ at $25^{\circ} \mathrm{C}$ in different solvents.

\begin{tabular}{lllllll}
\hline & DCM & NB & ACN & MeOH & DMF & $\mathrm{H}_{2} \mathrm{O}$ \\
\hline Compound 1 & 0.2 & 0.4 & 5 & 138 & 46 & 409 \\
Compound 2 & 1.1 & 4.2 & 30 & 152 & 79 & 432 \\
1:1 electrolytes & $10-20$ & $20-30$ & $120-160$ & $80-115$ & $65-90$ & $118-131$ \\
$1: 2$ electrolytes & $60-75$ & $50-60$ & $220-300$ & $160-220$ & $130-170$ & $235-273$ \\
$1: 3$ electrolytes & $-^{\mathrm{a}}$ & $70-80$ & $340-420$ & $-^{\mathrm{a}}$ & $200-240$ & $408-435$ \\
\hline
\end{tabular}

a. The standard value is not reported. 


\section{Supplementary material}

Syntheses and chromotropic behavior of two halo bridged dinuclear copper(II) complexes containing pyridine-based bidentate ligand

Atie Shirvan, Hamid Golchoubian*, Elisabeth Bouwman

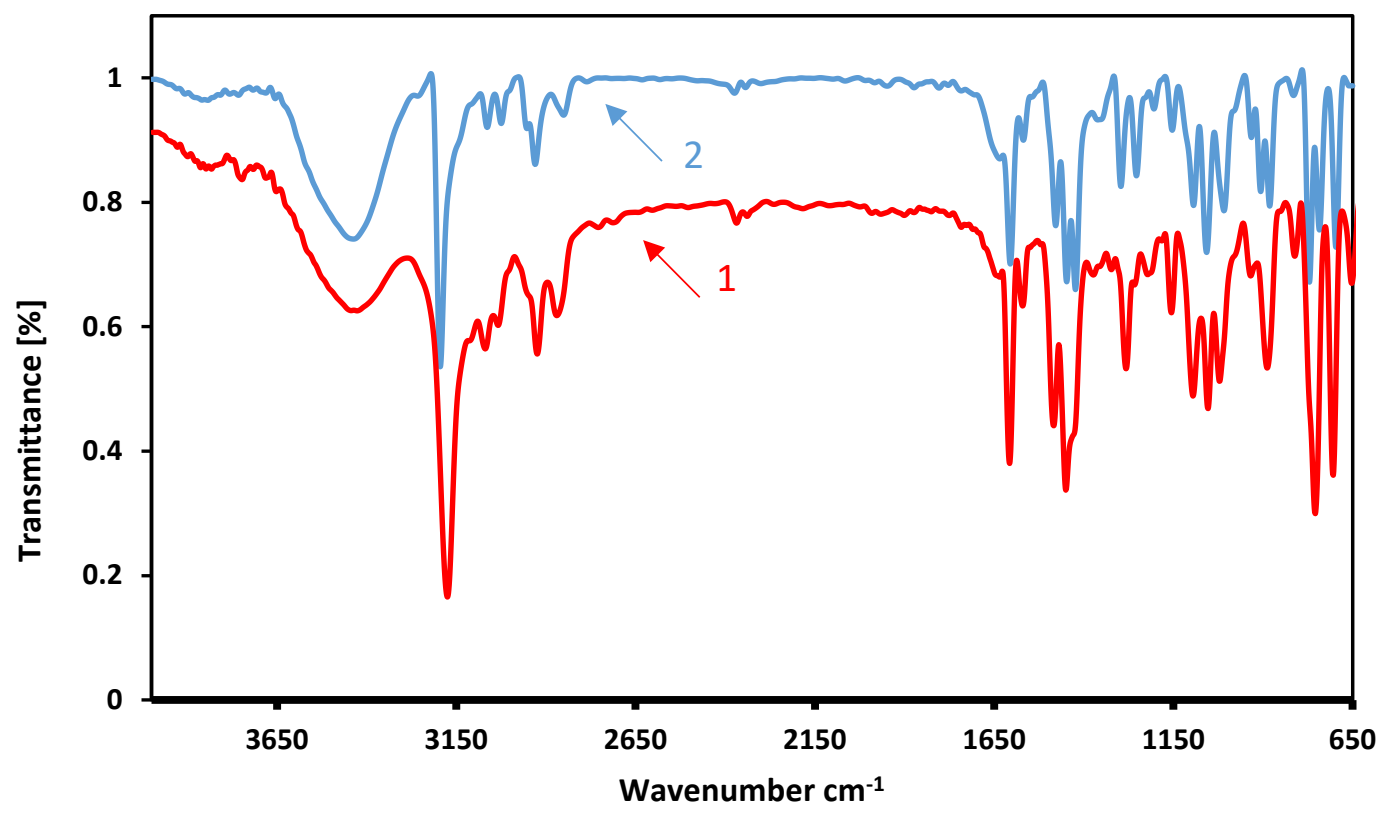

Figure S1. The infrared spectra of complexes $\mathbf{1}$ and $\mathbf{2}$. 

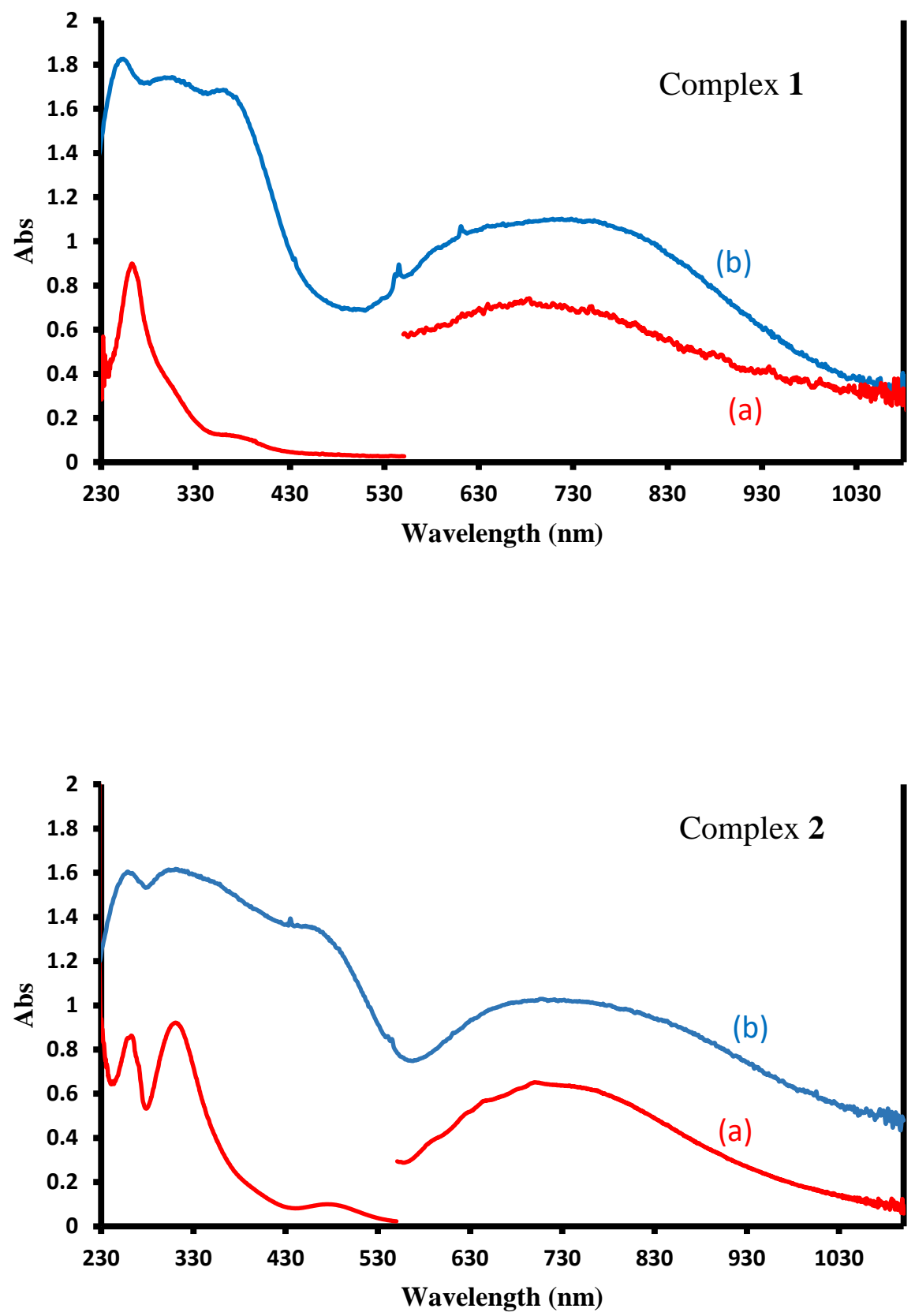

Figure S2. The comparison UV-Vis spectra of complexes 1 and 2 in DCM (a) and solid state (b). 


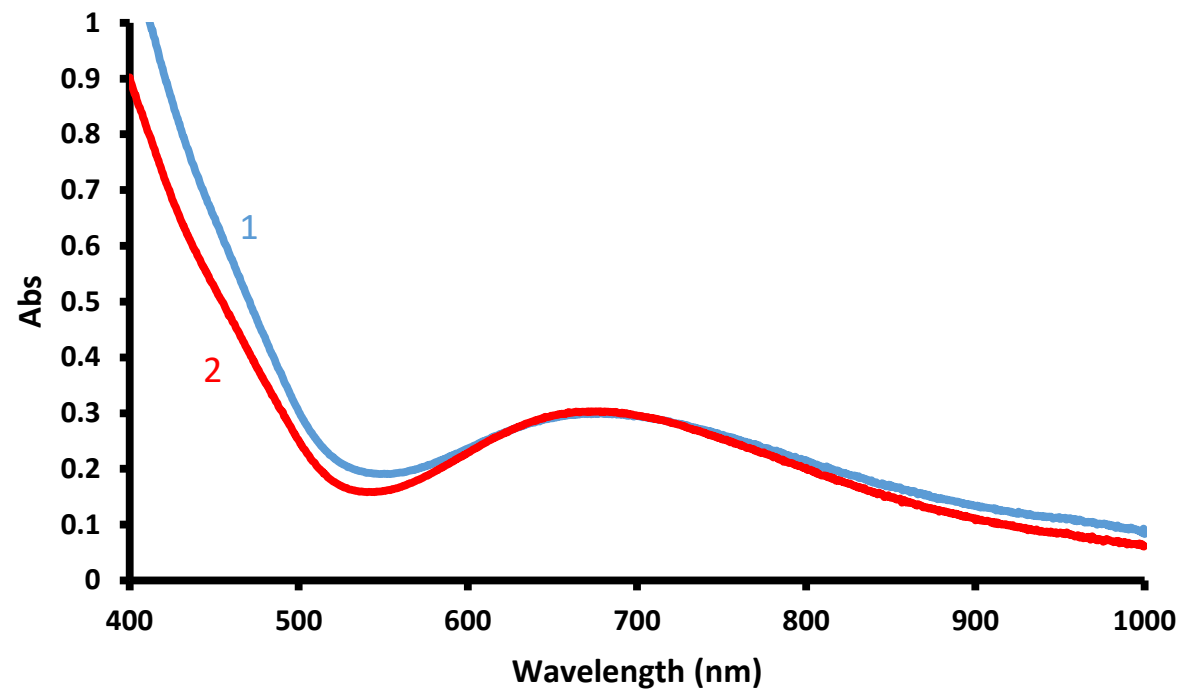

Figure S3. The visible spectra of complexes $\mathbf{1}$ and $\mathbf{2}$ in aqueous solution in original pH. 


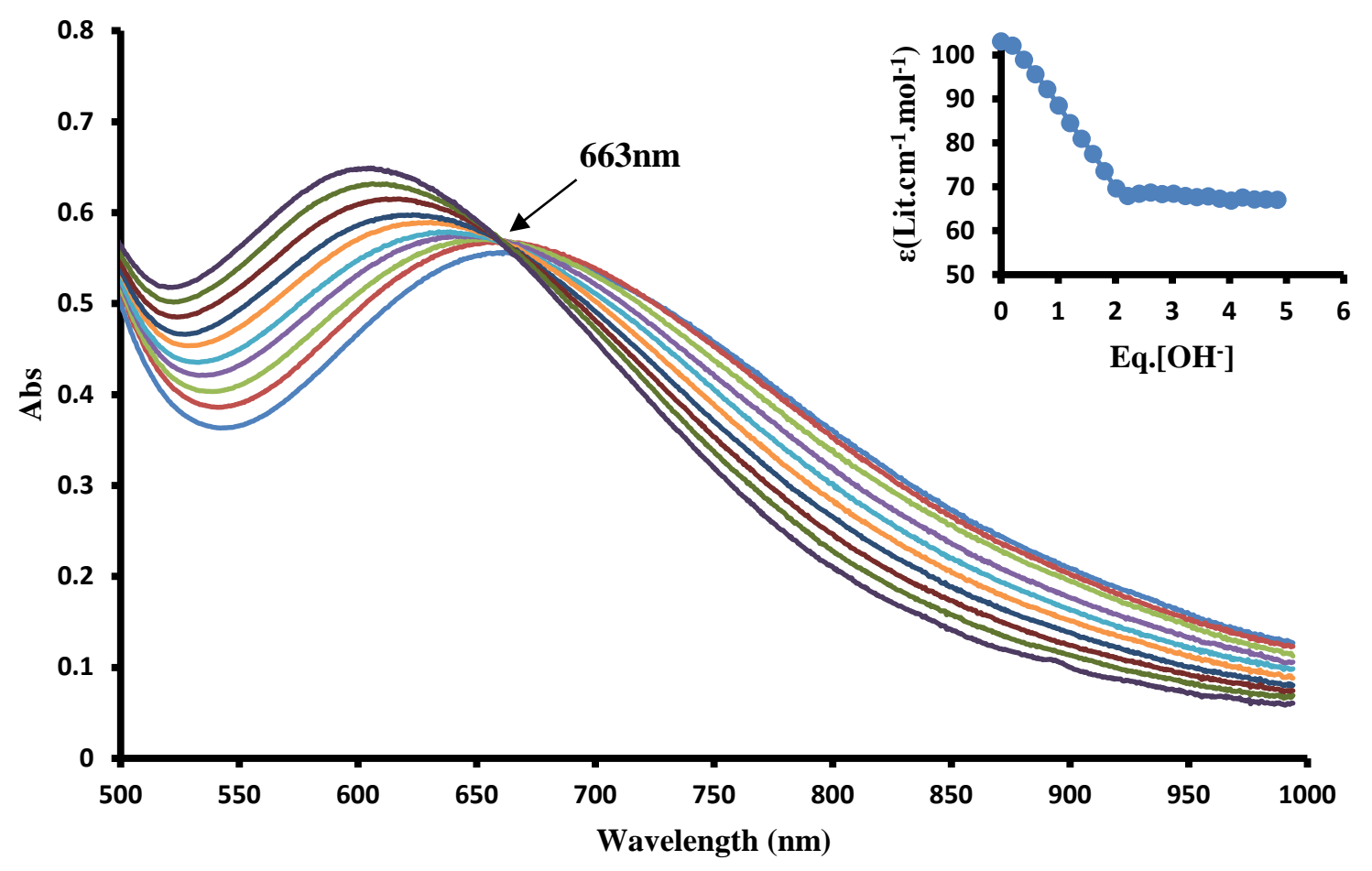

Figure S4. The $\mathrm{pH}$ titration of 2 with $\mathrm{NaOH}(0.1 \mathrm{M})$ in the $\mathrm{pH}$ range of 5.4-10.5. 


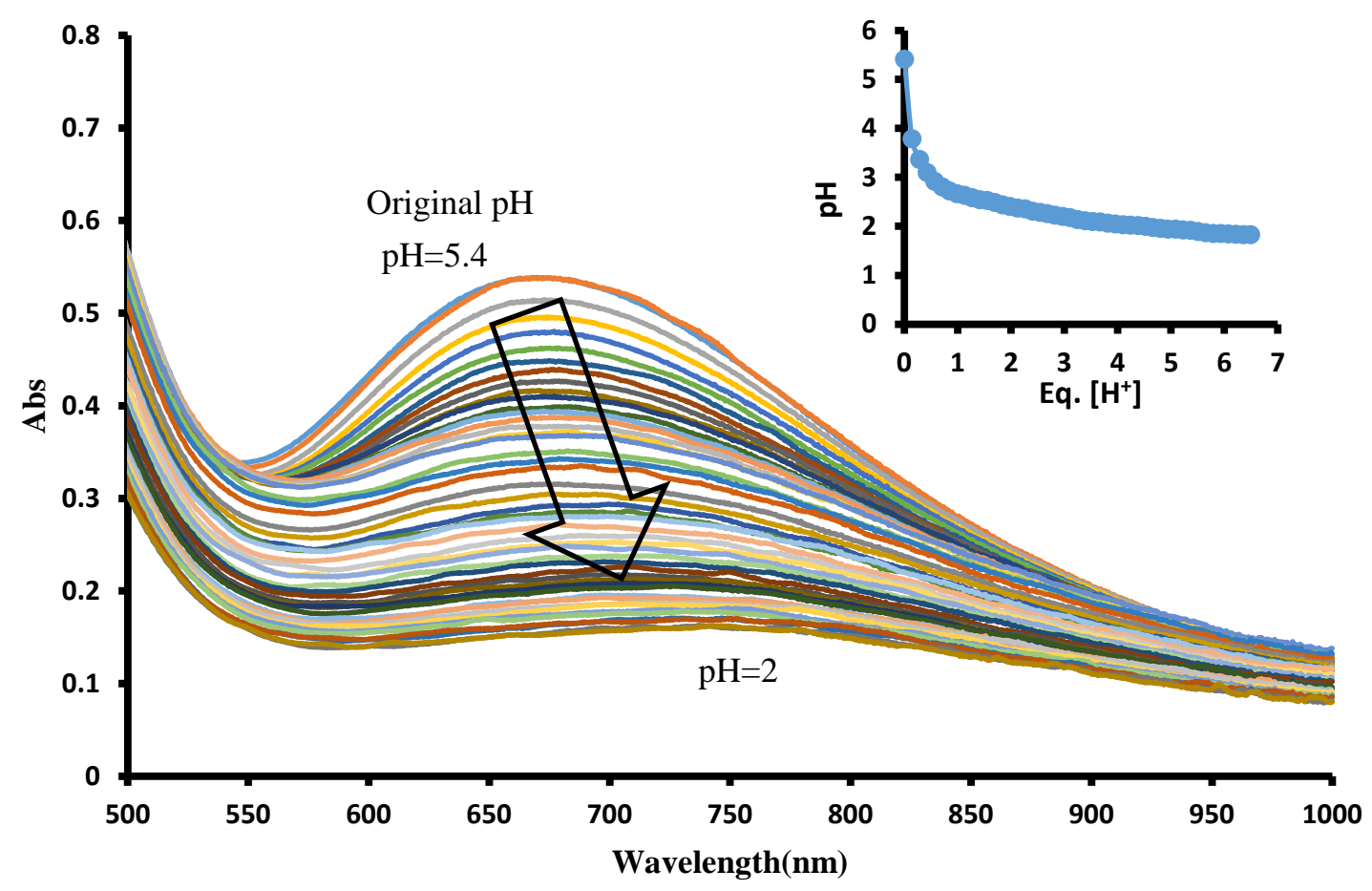

Figure S5. The $\mathrm{pH}$ titration of 2 with $\mathrm{HCl}(0.1 \mathrm{M})$ in the $\mathrm{pH}$ range of 5.4-2. 

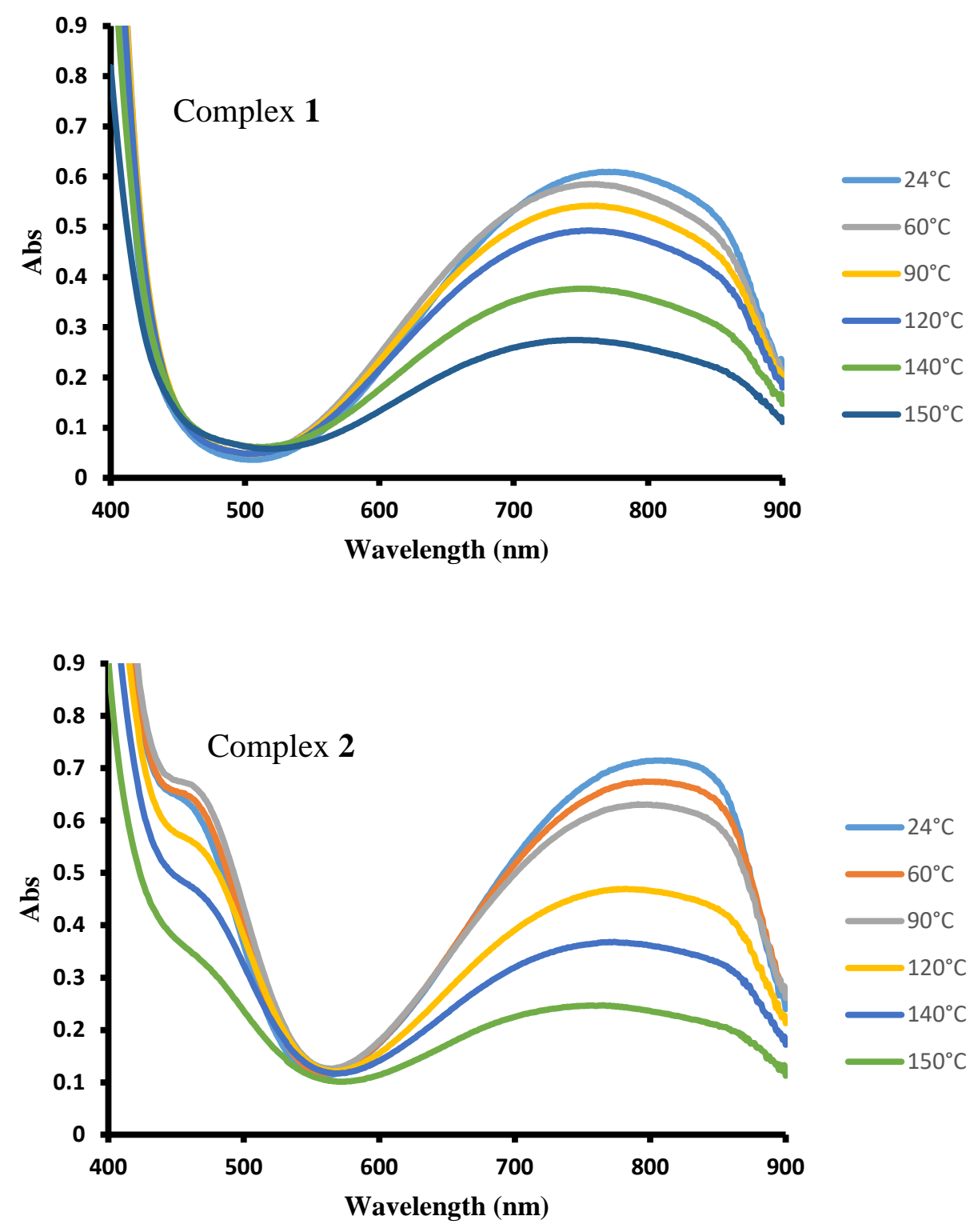

Figure S6. Temperature dependence of the visible absorbance of the complexes 1 and $\mathbf{2}$ in DMF. 